\title{
Estudo de inclusões fluidas em quartzo do garimpo do Papagaio, um sistema magmático-hidrotermal, Província Aurífera de Alta Floresta (MT), Cráton Amazônico
}

\author{
Fluid inclusions study on quartz from a magmatic-hydrothermal system in the Papagaio \\ Artisanal Mining District, Alta Floresta Gold Province, Mato Grosso state, Amazon Craton \\ Marcelo Garcia Galé1, Paulo César Corrêa da Costa², Rafael Rodrigues de Assis ${ }^{3}$, \\ Francisco Egídio Cavalcante Pinho², Caetano Juliani ${ }^{3}$ \\ ${ }^{1}$ Programa de Pós-Graduação em Geoquímica e Geotectônica, Instituto de Geociências, Universidade de São Paulo - USP, \\ Rua Virgulina Rios Salvato, 263, Jardim Patrícia, CEP 13807-751, Mogi Mirim, SP, BR (magagale@hotmail.com) \\ ²Faculdade de Geociências, Universidade Federal de Mato Grosso - UFMT, Cuiabá, MT, BR (pccorrea@cpd.ufmt.br; aguapei@yahoo.com) \\ ${ }^{3}$ Departamento de Geologia Sedimentar e Ambiental, Instituto de Geociências, Universidade de São Paulo - USP, São Paulo,
} SP, BR (assis.rafael@usp.br; cjuliani@usp.br)

Recebido em 11 de agosto de 2017; aceito em $1^{\circ}$ de fevereiro de 2018

\begin{abstract}
Resumo
O garimpo aurífero do Papagaio, localizado em Paranaíta, Mato Grosso, insere-se no setor noroeste da Província Aurífera de Alta Floresta, sul do Cráton Amazônico. Está hospedado em dacito porfirítico inicialmente afetado por alteração potássica, sobreposta por forte alteração sericítica pervasiva e, por fim, por alteração propilítica. O minério é representado pela paragênese pirita + calcopirita + esfalerita \pm galena \pm calcocita \pm covelita e ocorre associado a sistemas de veios de quartzo e stockworks que truncam os setores de alteração potássica e sericítica. Estudos de inclusões fluidas dos veios mineralizados e estéreis presentes no garimpo permitiram identificar três grupos de inclusões fluidas: tipo I) inclusões aquocarbônicas; tipo II) aquosas bifásicas; tipo III) aquosas tri a multifásicas. Nos veios mineralizados houve a crepitação das inclusões do Tipo I a $325^{\circ} \mathrm{C}$. Foram encontradas temperaturas de homogeneização de 115,1 a $216,2^{\circ} \mathrm{C}$ e salinidades entre 0,5 a $24,0 \%$ para as inclusões do Tipo II. Nos veios estéreis, as inclusões do Tipo II resultaram em temperaturas de homogeneização total entre 135,9 e $190,3^{\circ} \mathrm{C}$ e salinidades de 26,0 a 30,2\%. No Tipo III a homogeneização total ocorreu entre 323,2 e $402,9^{\circ} \mathrm{C}$ com salinidade superior a 40,0\%. Portanto, fluidos de elevada temperatura e salinidade com características de origem magmática tiveram um papel essencial na formação das zonas mineralizadas do garimpo. Nesse contexto, a colocação de corpos subvulcânicos teria sido essencial na gênese da mineralização aurífera do Papagaio, pois teria servido como fonte de calor, fluido e metais para a instalação de um sistema magmático-hidrotermal profundo, relacionado ao ambiente dos depósitos do tipo pórfiro e intrusion-related gold systems (IRGS).
\end{abstract}

Palavras-chave: Cráton Amazônico; Província Aurífera de Alta Floresta; Inclusões fluidas; Microtermometria; Fluidos magmáticos.

\begin{abstract}
The Papagaio artisanal gold mining in Paranaíta, Mato Grosso, Brazil, is located in the northwest sector of Alta Floresta Gold Province, in the southern Amazon Craton. Mineralization is hosted in porphyritic dacite initially affected by a potassic alteration that is superimposed by a strong pervasive sericitic alteration and, finally, by propylitic alteration. The ore paragenesis consists of pyrite + chalcopyrite + sphalerite \pm galena \pm chalcocite \pm covellite that is located in a quartz veins systems and stockworks that cuts hydrothermal potassic and sericitic alteration zones. Studies of fluid inclusions of the mineralized and barren veins present in the mining identified three groups of fluid inclusions: type I) aqueous-carbonic inclusions; type II) aqueous biphasic inclusions; type III) aqueous tri- to multiphase inclusions. In the mineralized veins, the type I inclusions decrepitated at $325^{\circ} \mathrm{C}$. Type II inclusions have homogenization temperatures of 115.1 to $216.2^{\circ} \mathrm{C}$ and salinities of 0.5 to $24.0 \%$. In the barren veins, type II inclusions yielded total homogenization temperatures between 135.9 and $190.3^{\circ} \mathrm{C}$ and salinities of 26.0 to $30.2 \%$. In type III inclusions, the total homogenization was between 323.2 and $402.9^{\circ} \mathrm{C}$
\end{abstract}


with salinity greater than $40.0 \%$. Therefore, high-temperature and high-salinity fluids with characteristics of magmatic origin had essential role in the formation of the mineralized zones of the artisanal mining. In this context, the placement of subvolcanic bodies would have been indispensable for the genesis of the gold mineralization at Papagaio. These subvolcanic bodies would have served as a source of heat, fluid, and metals for the development of a deep magmatic-hydrothermal system, possibly associated with the environment of the porphyry and intrusion-related gold systems (IRGS).

Keywords: Amazon Craton; Alta Floresta Gold Province; Fluid inclusions; Microthermometry; Magmatic fluids.

\section{INTRODUÇÃO}

A partir de meados da década de 1970, a região norte do estado de Mato Grosso passou a atrair atenção nacional devido ao início de atividades garimpeiras que se desenvolviam às margens do rio Teles Pires. O auge dessa atividade se estendeu até o final da década de 1990, com a descoberta de mais de uma centena de depósitos de pequeno porte $(<5 \mathrm{t})$ e de baixo a moderado teores, concentrados ao longo de uma faixa com mais de $500 \mathrm{~km}$ de extensão, estruturalmente orientada segundo W-NW, denominada Província Mineral Alta Floresta por Dardene e Schobbenhaus (2001), Província Aurífera Juruena-Teles Pires (Silva e Abram, 2008), Domínio Alta Floresta (Santos et al., 2001) e, em trabalhos mais recentes, Província Aurífera de Alta Floresta (PAAF) (Paes de Barros, 2007; Assis et al., 2014), como adotado neste trabalho.

O estudo da origem dos fluidos, bem como o entendimento de reações entre estes e suas rochas encaixantes, é fundamental para a compreensão da gênese e classificação de depósitos minerais hidrotermais. Nesse conceito, ao final dos anos 1990, iniciou-se uma série de pesquisas relacionadas à origem dos depósitos da província. Desde então, dados de isótopos estáveis e microtermométricos em inclusões fluidas têm evidenciado fluidos magmáticos como importantes contribuintes para as gêneses dos depósitos auríferos da PAAF (e.g., Moura, 1998; Botelho e Moura, 1998; Moura et al., 2006; Silva e Abram, 2008; Biondi, 2009; Rodrigues, 2012; Dias, 2012; Rambo, 2014; Serrato, 2014; Assis, 2015; Trevisan, 2015; Bettencourt et al., 2016).

Apesar de a província exibir grande potencial em hospedar mineralizações auríferas de natureza magmática-hidrotermal, sua geologia ainda necessita de estudos mais detalhados, particularmente em áreas-chave que permitam uma melhor definição do ambiente em que esses depósitos teriam se formado. Isso se torna mais crítico visto que a maior abrangência dos estudos, até então, era focada nos sistemas de $\mathrm{Au} \pm \mathrm{Cu}$ disseminados em rochas graníticas. Os depósitos filonares correspondem a uma das tipologias mais novas propostas para a província (Mesquita et al., 2015) e, apesar de sua importância econômica, estão relacionados ao grupo com o menor grau de conhecimento na PAAF quanto ao contexto geológico e metalogenético.
Neste sentido, o objetivo deste trabalho é caracterizar e contextualizar o regime de fluidos por meio da sistemática de inclusões fluidas (IFs) em veios de quartzo do garimpo do Papagaio, um sistema aurífero de $\mathrm{Au} \pm \mathrm{Cu} \pm \mathrm{Zn}$ confinado a stockworks e sistemas de veios alojados em zonas de alteração sericítica que afetam unidades vulcânicas de idade $1,78 \mathrm{Ga}$. No conjunto, esses resultados permitirão determinar as principais características físico-químicas dos fluidos responsáveis pelo evento mineralizante no depósito, possibilitando, portanto, uma avaliação mais consistente e crítica quanto ao seu modelo genético. Em adicional, permitirão uma melhor compreensão quanto à evolução dos sistemas magmático-hidrotermais responsáveis pela gênese das mineralizações auríferas na província.

\section{PROVÍNCIA AURÍFERA DE ALTA FLORESTA}

Situada na porção sul do Cráton Amazônico, a PAAF (Figura 1) engloba os limites entre as províncias geocronológicas Ventuari-Tapajós (1,95 a 1,8 Ga) e Rio NegroJuruena $(1,8-1,55 \mathrm{Ga})$ no modelo de Tassinari e Macambira $(1999,2004)$. Contudo, no modelo de Santos et al. (2000), a província insere-se entre as províncias tectônicas TapajósParima (2,03 - 1,88 Ga) e Rondônia-Juruena (1,82 - 1,54 Ga). Independentemente da compartimentação adotada, Tassinari (1996), Tassinari e Macambira (1999), Souza et al. (2005), Santos et al. (2006), Silva e Abram (2008) e Cordani et al. (2009) consideram que as unidades plutono-vulcânicas que compõem essas províncias foram geradas em ambiente de arcos magmáticos insulares que se desenvolveram e se agregaram progressivamente ao protocráton formado pela Província Amazônia Central no Paleoproterozoico. No entanto, a ausência de zonas de sutura, a abundância de sequências sedimentares continentais, os dados geoquímicos e isotópicos em unidades plutônicas e vulcânicas têm coletivamente indicado que a região teria se originado a partir da construção de arcos continentais (Juliani et al., 2013, 2014; Carneiro et al., 2014; Galé e Juliani, 2016).

O embasamento da PAAF é atualmente representado por dois complexos metamórficos, Bacareí-Mogno $(2,24 \mathrm{Ga}$; Pimentel, 2001) e Cuiú-Cuiú (1,99 Ga; Pessoa et al., 1977), que abrangem rochas metamórficas de médio a alto grau, 
além de plutônicas relacionadas a retrabalhamentos no decorrer do evento Jari-Falsino, entre 1,3 e 1,1 Ga (JICA; MMAJ, 2000).

Sobrepostas ao embasamento ocorrem vulcânicas e plutônicas ácidas a intermediárias, de idades paleo a mesoproterozoica (Figura 2), representadas pelo granito Nhandu $(1,88$ - 1,87 Ga), suíte intrusiva Matupá $(1,87$ $1,86 \mathrm{Ga}$ ), suíte Juruena (1,81 Ga), suíte São Pedro (1,78 Ga), grupo Colíder ( $1,78 \mathrm{Ga})$, suíte intrusiva Teles Pires $(1,78$ $1,75 \mathrm{Ga}$ ) e suíte Nova Canaã (1,74 Ga) (Souza et al., 2005;

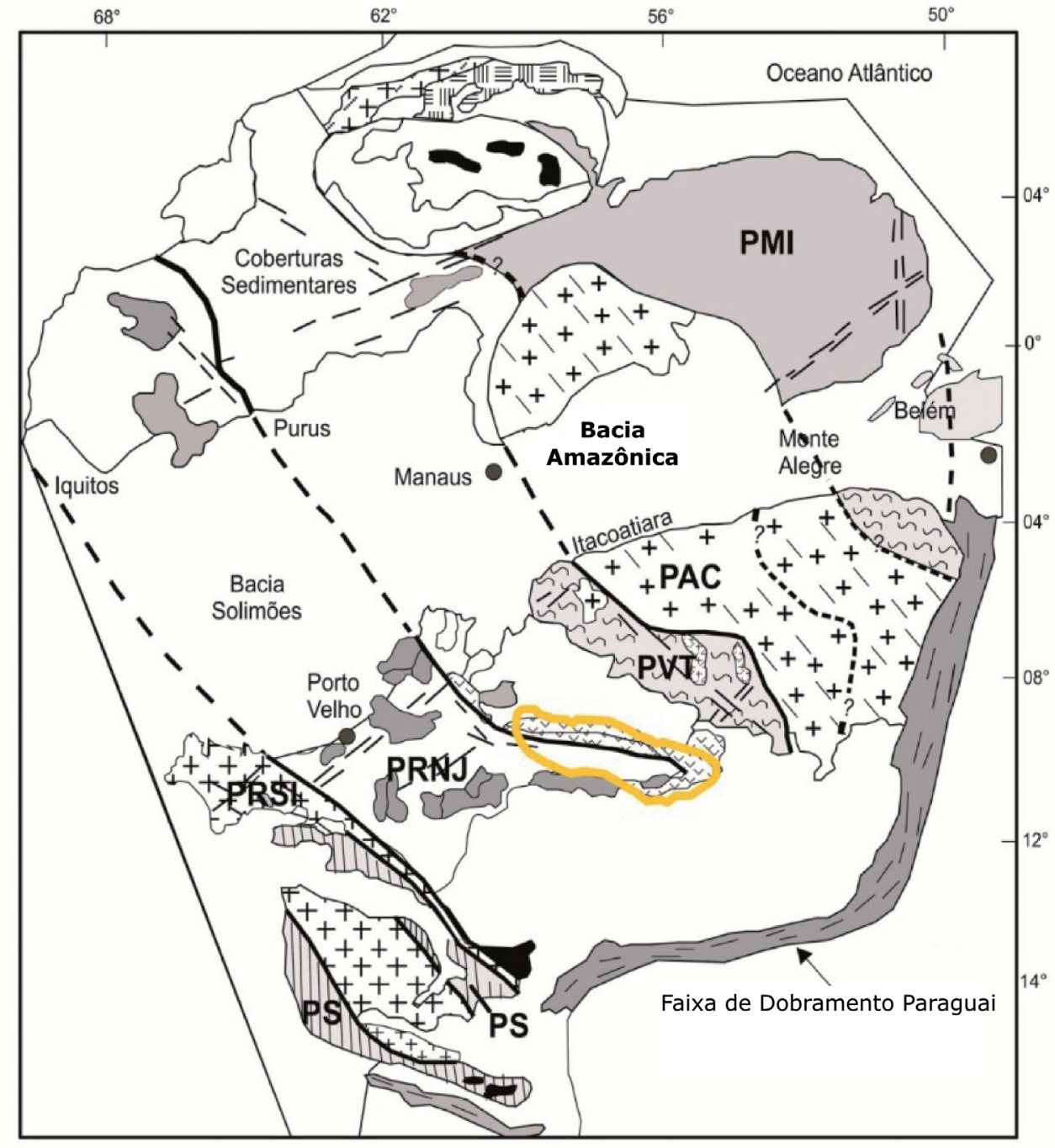

Limite PAAF

\section{Províncias Geocronológicas}

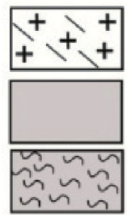

PAC - Amazônia Central: >2,3 Ga

PMI - Maroni-Itacaiúnas: 2,2 - 1,95 Ga

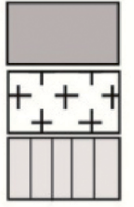

PRNJ - Rio Negro-Juruena: 1,8 - 1,55 Ga

PVT - Ventuarí-Tapajós: 1,95 - 1,8 Ga

PRSI - Rondoniana-San Ignácio: 1,5 - 1,15 Ga

PS - Sunsás: 1,1 - 0,9 Ga

Fonte: modificado de Tassinari e Macambira, 1999.

Figura 1. Localização da Província Aurífera de Alta Floresta na compartimentação geocronológica e tectônica do Cráton Amazônico. 


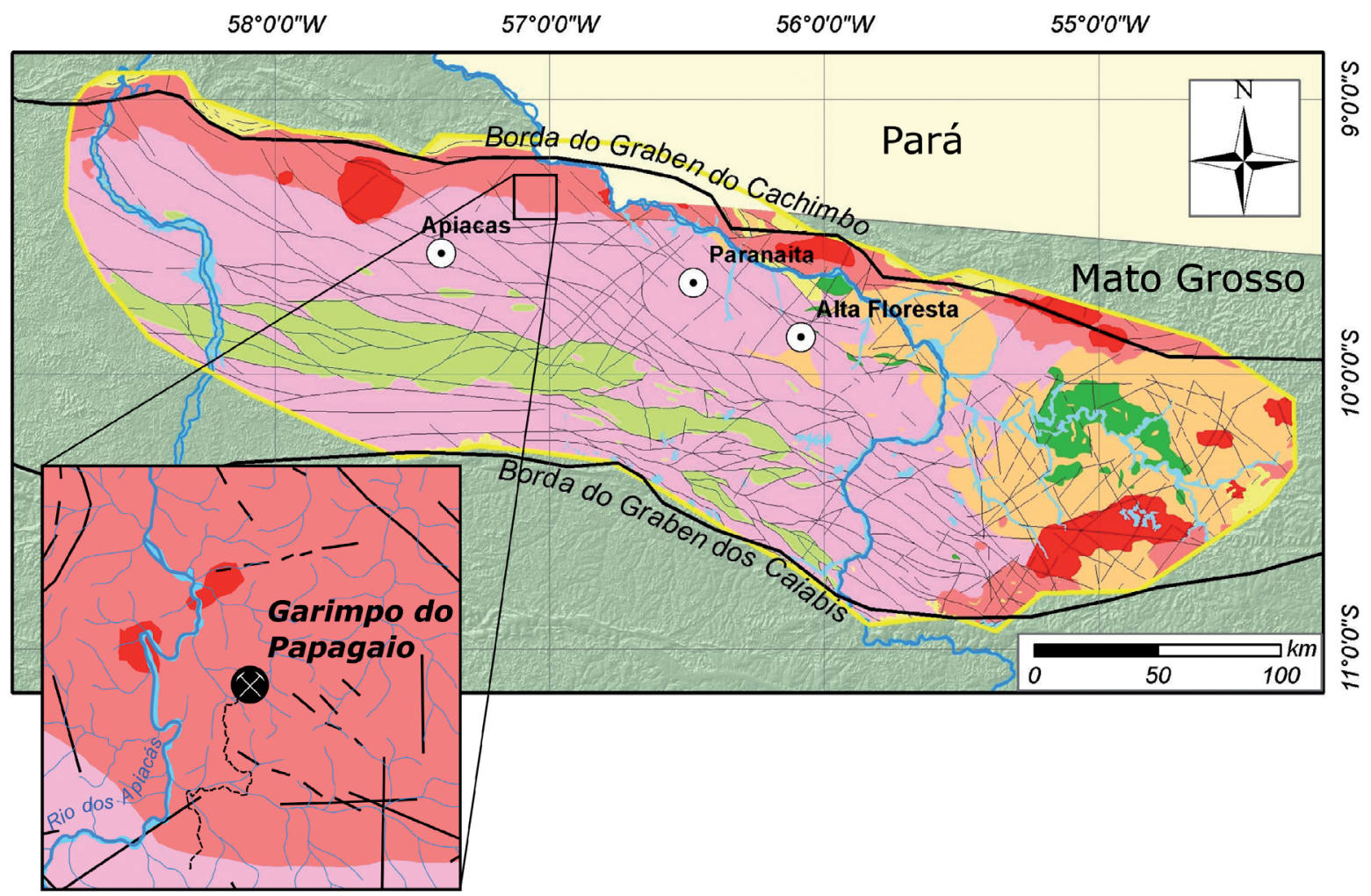

\section{Domínios geológicos \\ da Província Alta Floresta}

\begin{tabular}{|c|c|c|c|}
\hline ERA & Símbolo & Domínio geológico & $\begin{array}{c}\text { Unidades litológicas } \\
\text { e idade (Ma.) }\end{array}$ \\
\hline$<^{5}$ & & Coberturas superficiais & \begin{tabular}{|c|} 
Depósitos aluvionares \\
$\begin{array}{c}\text { Coberturas detrito-lateríticas } \\
\text { e ferruginosas }\end{array}$
\end{tabular} \\
\hline \multirow{8}{*}{$\begin{array}{l}\mathbf{8} \\
\mathbf{0} \\
\mathbf{0} \\
0 \\
\mathbf{1} \\
\mathbf{0} \\
\mathbf{0} \\
\mathbf{2}\end{array}$} & & $\begin{array}{c}\text { Bacias do tipo rift } \\
\text { e/ou graben }\end{array}$ & $\begin{array}{l}\text { Beneficente (<1714 U-Pb); } \\
\text { Dardanelos (<1383 U-Pb) }\end{array}$ \\
\hline & & Granitos anorogênicos & $\begin{array}{l}\text { Granito Teles Pires } \\
(1750 \mathrm{U}-\mathrm{Pb})\end{array}$ \\
\hline & & \multirow{3}{*}{$\begin{array}{l}\text { Granitos tardi a } \\
\text { pós-colisionais }\end{array}$} & $\begin{array}{l}\text { Granito São Romão } \\
\text { (1770 U-Pb) }\end{array}$ \\
\hline & & & Intrusivas máficas Guadalupe \\
\hline & & & $\begin{array}{c}\text { Paranaíta (?) } \\
\text { Nova Canaaã (1743 U-Pb) } \\
\text { Apiacás (1780 - } 1700 \text { U-Pb) } \\
\text { São Pedro (1784 U-Pb) } \\
\text { Juruena (1810 U-Pb) }\end{array}$ \\
\hline & & $\begin{array}{c}\text { Sequência de arco vulcânico } \\
\text { e intra-arco }\end{array}$ & $\begin{array}{c}\text { Suite Colider } \\
(1781-1801 \mathrm{U}-\mathrm{Pb})\end{array}$ \\
\hline & & $\begin{array}{l}\text { Complexo metamórfico } \\
\text { Granitos pós-orogênicos }\end{array}$ & $\begin{array}{c}\text { Complexo Bacaeri-Mogno } \\
\text { Nova Monte Verde (1785 U-Pb) } \\
\text { Suíte Vitória; seq. vulcano } \\
\text { sedimentar Marcelo Cabeça } \\
\text { Granito Nhandu (1800 U-Pb) } \\
\text { Suíte Intrusiva Matupa } \\
\text { (1872 Pb-Pb) }\end{array}$ \\
\hline & & Terrenos granito-gnaisse & $\begin{array}{l}\text { Complexo Cuiú-Cuiú } \\
(2005 \text { - } 2030 \text { U-Pb) }\end{array}$ \\
\hline
\end{tabular}
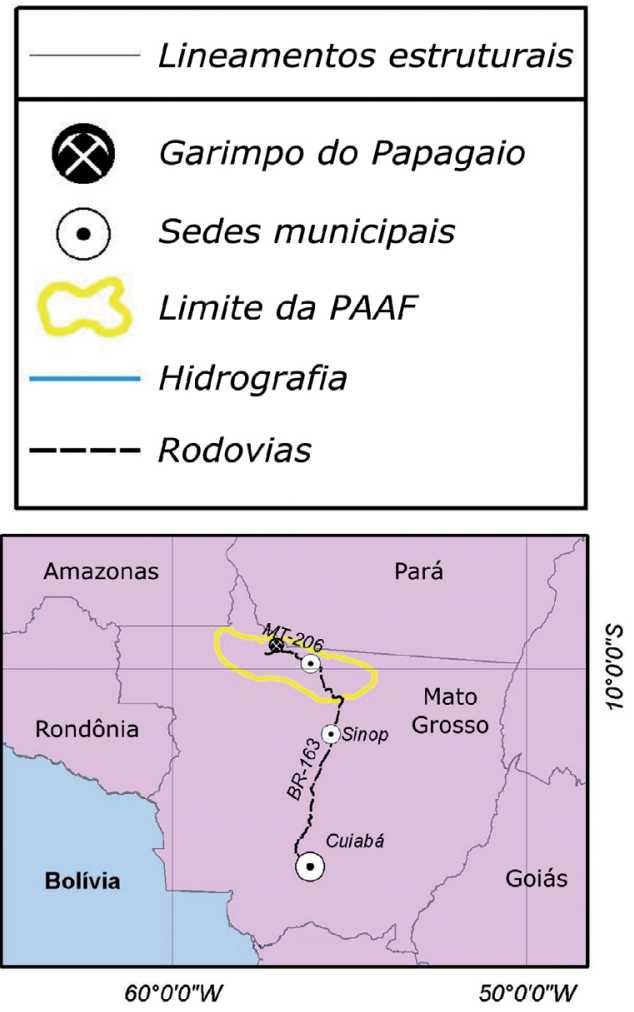

Fonte: compilado de Lacerda Filho et al., 2004; Souza et al., 2005; Paes de Barros, 2007.

Figura 2. Localização e domínios geológicos da Província Aurífera de Alta Floresta. 
Silva e Abram, 2008; Paes de Barros, 2007; Barros et al., 2009; Assis, 2015). Essas unidades são recobertas por sedimentos plataformais mesoproterozoicos do grupo beneficente, depositados em rift continental de direção SE-NW, originado por pelo menos dois pulsos tafrogênicos, de idades 1,72 e 1,36 Ga (Leite e Saes, 2003).

As mineralizações na PAAF são predominantemente auríferas e ocorrem alinhadas ao longo de um cinturão de direção NW-SE, denominado Peru-Trairão (Assis et al., 2014). Com base na alteração hidrotermal, paragênese, estilo e geoquímica do minério, tais depósitos têm sido agrupados em quatro tipologias principais:

(i) depósitos de $\mathrm{Au} \pm \mathrm{Cu}$ disseminados (e.g., depósitos Luizão, Pé Quente, Serrinha e X1);

(ii) depósitos filonares de $\mathrm{Au} \pm \mathrm{Cu}$ (e.g., Edu, Peteca, Paraíba e Basílio), ambos dominantemente representados por pirita com concentrações variáveis de calcopirita e hematita;

(iii) depósitos disseminados de $\mathrm{Cu}+\mathrm{Mo} \pm \mathrm{Au}$ (e.g., Ana e Jaca), com pirita, molibdenita e concentrações variáveis de hematita e calcopirita;

(iv) depósitos de $\mathrm{Au}+\mathrm{Zn}+\mathrm{Pb} \pm \mathrm{Cu}$ (e.g., depósito do Francisco, Bigode e Luiz) representados por pirita + esfalerita + galena, além de calcopirita e digenita subordinadas.

A grande maioria dos depósitos, inserida nos grupos $1 \mathrm{e}$ 2 , encontra-se principalmente hospedada em sistemas graníticos cálcio-alcalinos oxidados (granitos tipo I; portadores de magnetita) e, portanto, possivelmente equivalentes a sistemas magmático-hidrotermais do tipo Au-pórfiro. Os grupos 3 e 4 , no entanto, por estarem hospedados em subvulcânicas, vulcanossedimentares e granitos alcalinos epizonais oxidados (granitos tipo $\mathrm{A}_{2}$ ), exibem atributos geológicos compatíveis com os sistemas epitermais de low a intermediate sulfidation (Assis et al., 2014; Bettencourt et al., 2016).

\section{MATERIAIS E MÉTODOS}

A caracterização da rocha hospedeira e das alterações hidrotermais foi feita a partir da descrição macroscópica de amostras provenientes dos testemunhos de sondagens executados nas proximidades das cavas garimpeiras.

Os estudos de IFs e a identificação dos minerais de minério foram efetuados a partir de quatro lâminas bipolidas representativas de veios de quartzo coletadas diretamente nas cavas do garimpo do Papagaio. Foram analisados cristais de quartzo provenientes de veios estéreis e mineralizados que cortam as rochas hospedeiras do depósito. Esse estudo focou a descrição e caracterização dos tipos e grupos de inclusões, assim como individualizou-as em assembleias.

A petrografia das IFs foi realizada à temperatura ambiente $\left(25^{\circ} \mathrm{C}\right)$ em lâminas bipolidas confeccionadas no Laboratório de Laminação da Universidade Estadual de Campinas (UNICAMP). A caracterização petrográfica das IFs foi realizada, de acordo com a metodologia proposta por Roedder (1984), Bodnar (2003) e Goldstein (2003), em um microscópio petrográfico convencional da ZEISS Axiophot e Leica DM-EP. As análises microtermométricas foram obtidas no laboratório de Microtermometria do Instituto de Geociências da Universidade Estadual de Campinas (IG-UNICAMP), em uma platina de aquecimento/resfriamento LINKAM THMSG600 adaptada a um microscópio convencional LEICA ${ }^{\circledR}$ DMLP, com calibração em inclusões sintéticas aquosalinas e aquocarbônicas manufaturadas pela SYN FLINC. Os cálculos referentes à salinidade das inclusões foram efetuados a partir da equação de Bodnar (2003) para as inclusões aquosas bifásicas e Diamond (1992) para as inclusões aquocarbônicas.

Os cálculos de estimativa de pressão dos fluidos hidrotermais foram efetuados em software FLINCOR, a partir da metodologia proposta por Bakker (2003).

\section{GEOLOGIA DO GARIMPO DO PAPAGAIO}

Localizado à margem direita do Rio Apiacás (Figura 2), o garimpo aurífero do Papagaio corresponde a um complexo de shafts e cavas inseridos em um morrote que se destaca no relevo local, em uma região com perfis pedogenéticos relativamente bem desenvolvidos, o que dificulta a ocorrência de afloramentos contínuos e representativos.

As zonas mineralizadas ocorrem hospedadas em um dacito cinza-escuro de textura porfirítica bem desenvolvida e fortemente magnético devido à presença de magnetita. Os fenocristais de plagioclásio, dispersos em matriz afanítica, não ultrapassam $30 \%$ do volume total da rocha e exibem comprimentos que variam de 0,5 a $3,0 \mathrm{~mm}$ (Figura 3A). Embora foliações cataclásticas e miloníticas tenham sido localmente observadas nas zonas de falhas por Quaresma e Hatanaka (2011), indícios de deformação regional estão ausentes. Adicionalmente, a rocha exibe afinidades geoquímicas calcioalcalinas de médio a alto K (Galé et al., 2015). Galé (2012) reporta idade concordante de cristalização para a hospedeira dacítica, pelo método U-Pb em zircão por LA-ICP-MS, de $1781,4 \pm 7,5 \mathrm{Ma}(\mathrm{MSWD}=1,3 ; \mathrm{n}=20)$.

\section{Alteração hidrotermal}

A alteração hidrotermal afetou generalizadamente a rocha hospedeira do garimpo do Papagaio, mas em intensidade variada, concentrando-se particularmente nas salbandas dos veios mineralizados. Foram reconhecidas quatro tipologias principais da alteração hidrotermal relacionadas à mineralização, temporalmente sequenciadas em: 
(i) alteração potássica;

(ii) alteração sericítica;

(iii) alteração sílica;

(iv) alteração propilítica.

Em adicional, silicificação tardia é representada por veios de quartzo estéreis. A evolução paragenética dos minerais que se cristalizaram durante a fase magmática e, posteriormente, na fase hidrotermal pode ser observada na Tabela 1.

A alteração potássica pervasiva corresponde ao primeiro estágio hidrotermal reconhecido, exibe paragênese microclínio + biotita \pm quartzo \pm hematita e confere a característica tonalidade avermelhada à rocha (Figura 3B), ao longo de halos centimétricos $(>2 \mathrm{~cm})$ a pouco mais de um metro. Ocorre, sobretudo, a partir da substituição parcial ou total do plagioclásio ígneo. Seguiu-se um estágio de alteração sericítica pervasiva a fissural, representada pela paragênese quartzo + sericita + pirita (QSP), que altera as tonalidades das rochas para acinzentadas e, por vezes, descaracteriza a textura porfirítica original (Figura 3C), muitas vezes com formação de pseudomorfos de sericita. A alteração sílica é fissural e encontrada na forma de veios e vênulas de quartzo que, embora possam ocorrer em dimensões maiores, variam principalmente entre 0,5 e $2 \mathrm{~cm}$ de largura e cortam as alterações anteriores. Finalmente, observa-se alteração propilítica pervasiva e fissural de intensidade moderada a fraca e tardia, que ocorre regionalmente e oblitera as tipologias citadas, representada pela associação epídoto + clorita + apatita \pm carbonatos \pm actinolita \pm albita \pm sericita (Figura 3D). Tipicamente substitui os núcleos mais cálcicos do plagioclásio e do feldspato potássico hidrotermal e, quando fissural, ocorre na forma de vênulas de epídoto + clorita \pm carbonatos.

\section{Estilo e paragênese do minério}

As zonas mineralizadas no garimpo do Papagaio estão relacionadas aos sistemas de veios de quartzo e stockworks das

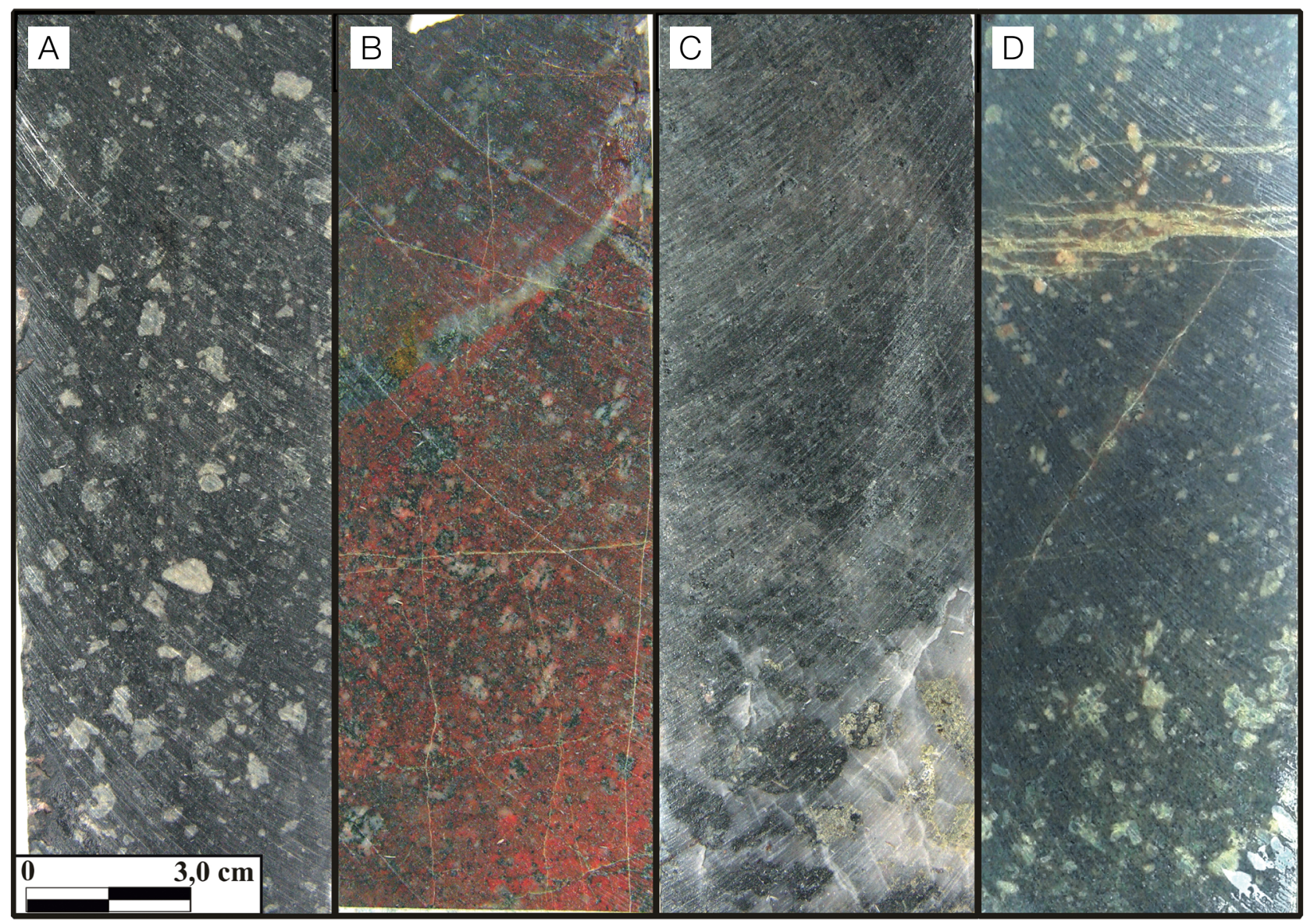

Figura 3. (A) Dacito porfirítico que hospeda o minério aurífero no garimpo do Papagaio; (B) alteração potássica pervasiva à base de microclínio, responsável pelas tonalidades avermelhadas da hospedeira; (C) alteração sericítica pervasiva responsável pela não preservação da textura ígnea do dacito hospedeiro; (D) alteração propilítica pervasiva que configura tonalidade esverdeada à hospedeira, além de vênulas tardias de epídoto que truncam os estágios anteriores da alteração hidrotermal. 
regiões de intensa silicificação e, subordinadamente, ocorrem sulfetos disseminados nos halos de alteração potássica e sericítica.

O minério venular (Figura 4A) ocorre preferencialmente em veios de direção $\mathrm{N} 40^{\circ} \mathrm{E}$ com mergulhos subverticais que se alternam de NW para SE. A associação do minério é representada por pirita $(5-90 \%)$, calcopirita $(10-30 \%)$, esfalerita $(2-30 \%)$, além de galena, calcocita e covelita ( $2 \%)$ subordinada. Um segundo sistema de veios, contudo, estéreis e menos frequentes, ocorre em direção perpendicu$\operatorname{lar}(\mathrm{NW})$ ao primeiro conjunto.

A pirita é o sulfeto mais abundante em todo o sistema hidrotermal, ocorre como cristais euédricos a subédricos de granulação fina a média (Figuras 4A e 4B) e está presente em todas as gerações de veios e vênulas associados ao minério. Nos veios mais tardios, no entanto, calcopirita e esfalerita são comumente encontradas e podem, até mesmo, se tornar dominantes sob a pirita em alguns casos (Figura 4C). A calcopirita forma cristais anédricos, comumente associada ou, até mesmo, como pequenas inclusões na esfalerita, caracterizando a textura da "doença da calcopirita" (chalcopyrite disease) (Barton e Bethke, 1987; Nagase e Kojima, 1997). A esfalerita ocorre normalmente nas zonas mais centrais dos veios de quartzo ou mesmo preenchendo fraturas, indício de que, junto com a calcopirita, estaria associada a uma fase mais tardia do evento hidrotermal mineralizante. Pode ser maciça, formar cristais anédricos, amigdaloidais ou mesmo veios. Galena, calcocita e covelita são minerais acessórios, e os dois últimos representam estágios mais tardios e relacionados à substituição da calcopirita.

O minério disseminado ocorre de forma sutil nos halos da alteração sericítica e, raramente, na alteração potássica. Esse domínio é eminentemente representado por pirita, que ocorre como cristais dispersos de hábitos euédricos a subédricos de granulação fina.

O ouro não foi observado em microscópio petrográfico convencional, o que sugere sua ocorrência preferencial como microinclusões na pirita e/ou calcopirita.

\section{INCLUSÕES FLUIDAS}

Com o objetivo de distinguir os atributos físico-químicos (e.g., temperatura, salinidade, composição) do fluido hidrotermal e mecanismos de precipitação do minério operantes no garimpo do Papagaio, os estudos de IFs foram efetuados em cristais de quartzo provenientes tanto de veios mineralizados quanto de veios estéreis. Essa sistemática buscou encontrar eventuais diferenças genéticas entre os distintos sistemas de veios do depósito.

Considerando as relações de fases observadas à temperatura ambiente $\left(25^{\circ} \mathrm{C}\right)$, as IFs analisadas, independentemente de suas proveniências, podem ser agrupadas nas seguintes tipologias:

- inclusões aquocarbônicas, com ocorrência restrita de cristais sólidos $\left(\mathrm{L}_{\mathrm{H}_{2} \mathrm{O}}+\mathrm{L}_{\mathrm{CO}_{2}}+\mathrm{V}_{\mathrm{CO}_{2}} \pm \mathrm{S}\right)$;

Tabela 1. Quadro paragenético com a evolução temporal do paleossistema hidrotermal do garimpo do Papagaio.

\begin{tabular}{|c|c|c|c|c|c|c|c|}
\hline \multicolumn{2}{|c|}{ Mineral Fase } & $\begin{array}{c}\text { Cristalizaçãoo } \\
\text { magmática }\end{array}$ & $\begin{array}{l}\text { Alteração } \\
\text { potássica }\end{array}$ & $\begin{array}{l}\text { Alteração } \\
\text { sericítica } \\
\end{array}$ & $\begin{array}{c}\begin{array}{c}\text { Silicificação } \\
\text { (veios mineralizados) }\end{array} \\
\end{array}$ & $\begin{array}{l}\text { Alteração } \\
\text { propilítica }\end{array}$ & $\begin{array}{c}\text { Silicificação } \\
\text { (veios estéreis) }\end{array}$ \\
\hline 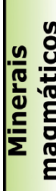 & $\begin{array}{l}\text { Plagioclásio } \\
\text { Quartzo } \\
\text { Biotita } \\
\text { K-feldspato }\end{array}$ & 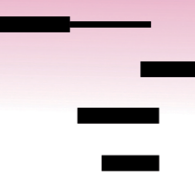 & & & & & \\
\hline \multirow{15}{*}{ 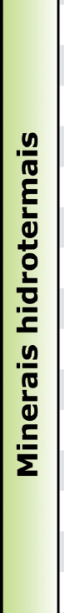 } & Quartzo & & & - & & - & \\
\hline & Microclínio & & $F$ & & & & \\
\hline & Biotita & & $\Rightarrow$ & & & & \\
\hline & Sericita & & & - & & & \\
\hline & Pirita & & & 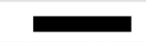 & = & & \\
\hline & Calcopirita & & & 一 & - & & \\
\hline & Hematita & & & & & & \\
\hline & Esfalerita & & & & E & & \\
\hline & Ouro & & & & - & & \\
\hline & Galena & & & & - & & \\
\hline & Magnetita & & & & - & & \\
\hline & Epidoto & & & & & & \\
\hline & Clorita & & & & & & \\
\hline & Apatita & & & & & - & \\
\hline & Carbonato & & & & & & \\
\hline
\end{tabular}


- inclusões aquosas bifásicas $\left(\mathrm{L}_{\mathrm{H}_{2} \mathrm{O}}+\mathrm{V}_{\mathrm{H}_{2} \mathrm{O}}\right)$;

- inclusões aquosas tri a multifásicas $\left(\mathrm{L}_{\mathrm{H}_{2} \mathrm{O}}^{2}+\mathrm{V}_{\mathrm{H}_{2} \mathrm{O}}+\mathrm{S}\right)$, portadoras de sólidos que, por vezes, apresentam índices de refração semelhantes aos do quartzo hospedeiro e hábito cúbico, sugestivos de corresponderem a cristais de saturação de halita.

Em menor proporção também foram observadas IFs monofásicas, possivelmente preenchidas apenas por $\mathrm{H}_{2} \mathrm{O}_{(1)}$, que ocorrem juntamente com inclusões dos tipos II e III. IFs carbônicas monofásicas também estão presentes, no entanto, em número reduzido no grupo I.

\section{Veios mineralizados}

Apresentam espessura geralmente inferior a $7 \mathrm{~cm}$, orientação para NE com mergulho subvertical e/ou dispostos em sistemas stockworks pouco desenvolvidos, similares a diversos outros sistemas mineralizados descritos no setor leste da província, a exemplo dos depósitos Luizão e Francisco
(Paes de Barros, 2007; Assis, 2011; Assis et al., 2014). Os cristais de quartzo analisados exibem granulação média a fina e são provenientes de veios com pirita + calcopirita + esfalerita \pm galena \pm calcocita \pm covelita.

Nessa tipologia de veios, os fluidos são representados por inclusões pertencentes aos tipos I, II e III. Independentemente do grupo tipológico, todas as inclusões apresentaram formas arredondadas a irregulares, com dimensões que não excedem os $12 \mu \mathrm{m}$ de comprimento. As inclusões do Tipo I são primárias, ocorrem preferencialmente em nuvens isoladas ou em linhas orientadas ao longo das bordas de crescimento do cristal e raramente coexistem com as dos tipos II e III. Porém, quando coexistentes, feições de estrangulamento (necking down) são frequentes (Figuras 5A e 5B). A porcentagem da fase de vapor $\left(\mathrm{V}_{\mathrm{CO}}\right)$ é amplamente variável, de $20 \mathrm{a}$ $90 \%$ do volume total da inclusão (moda entre 50 e 70\%; Figura 6). As inclusões do Tipo II são mais frequentes e podem coexistir com as do Tipo III, ao longo de nuvens isoladas ou trilhas secundárias (Figura 5C). São inclusões
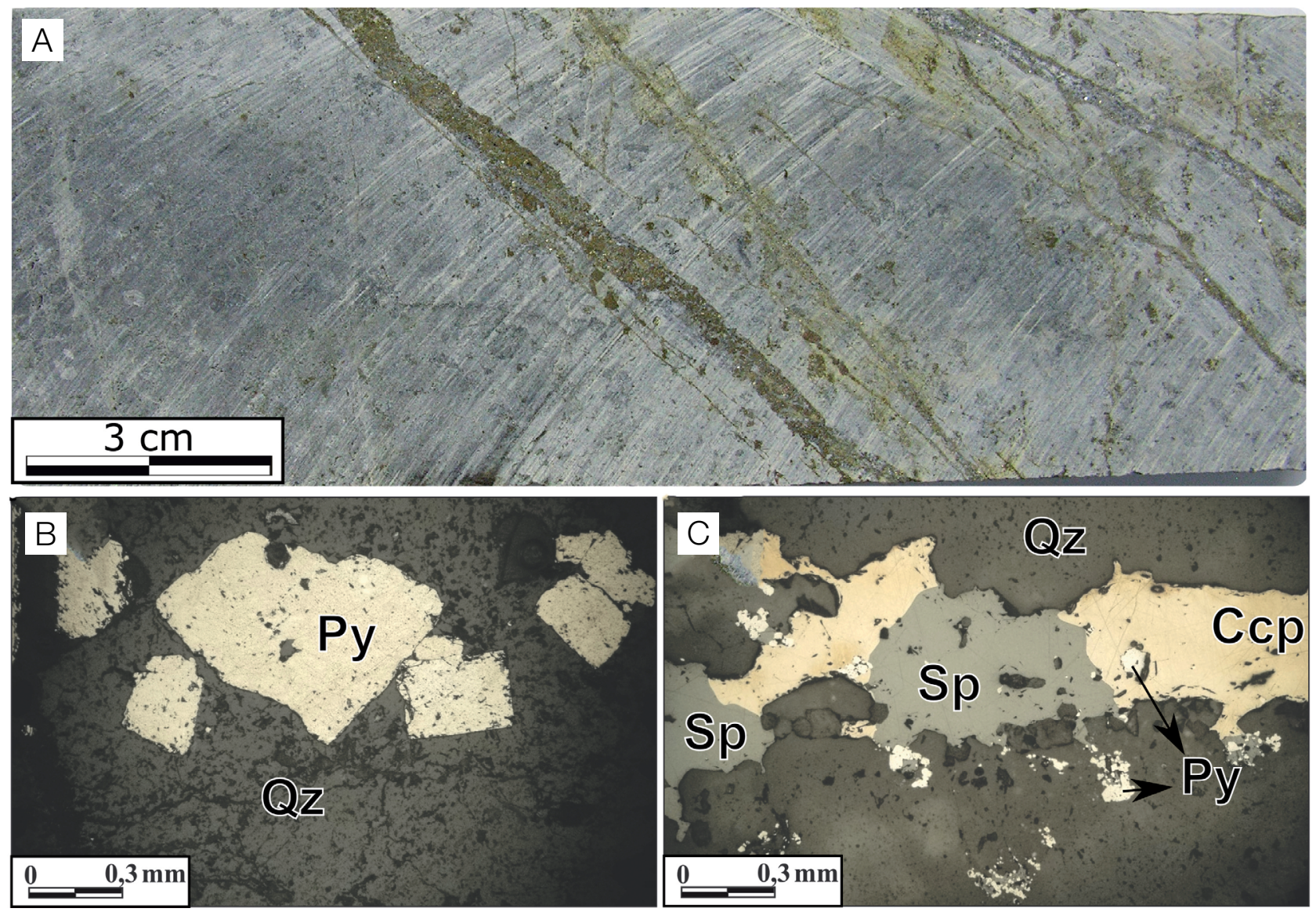

Py: pirita; Qz: quartzo; Ccp: calcopirita; Sp: esfalerita.

Figura 4. (A) Pirita associada a veios de quartzo que truncam zonas de alteração sericítica em hospedeira dacítica; (B) pirita euédrica a subeuédrica em veio mineralizado. (C) paragênese representada por calcopirita + esfalerita + pirita em veios mineralizados. FOTOMICROGRAFIAS: Iuz refletida. 
que exibem grande homogeneidade quanto à porcentagem da fase volátil $\left(10 \%<\mathrm{V}_{\mathrm{H}_{2} \mathrm{O}}<\mathrm{a} 30 \%\right)$, portanto, sem evidências de boiling, o que sugere fluido capturado em alta pressão decorrente de um nível crustal profundo. As inclusões do Tipo III, mais frequentes em zonas de alteração propilítica intensa, são tri a multifásicas e frequentemente apresentam mais de um cristal de saturação (CS) incluso. Esses cristais de saturação exibem formatos heterogêneos, de cúbico a acicular, e ocupam entre
2 e $70 \%$ do volume total da inclusão (Figuras $5 \mathrm{D}$ a $5 \mathrm{G}$ ), sugerindo o aprisionamento acidental de sólidos de composição variada.

\section{Veios estéreis}

Os veios estéreis são mais novos do que os mineralizados e formados por cristais de quartzo de dimensões regulares e granulação muito grossa. Os fluidos são eminentemente
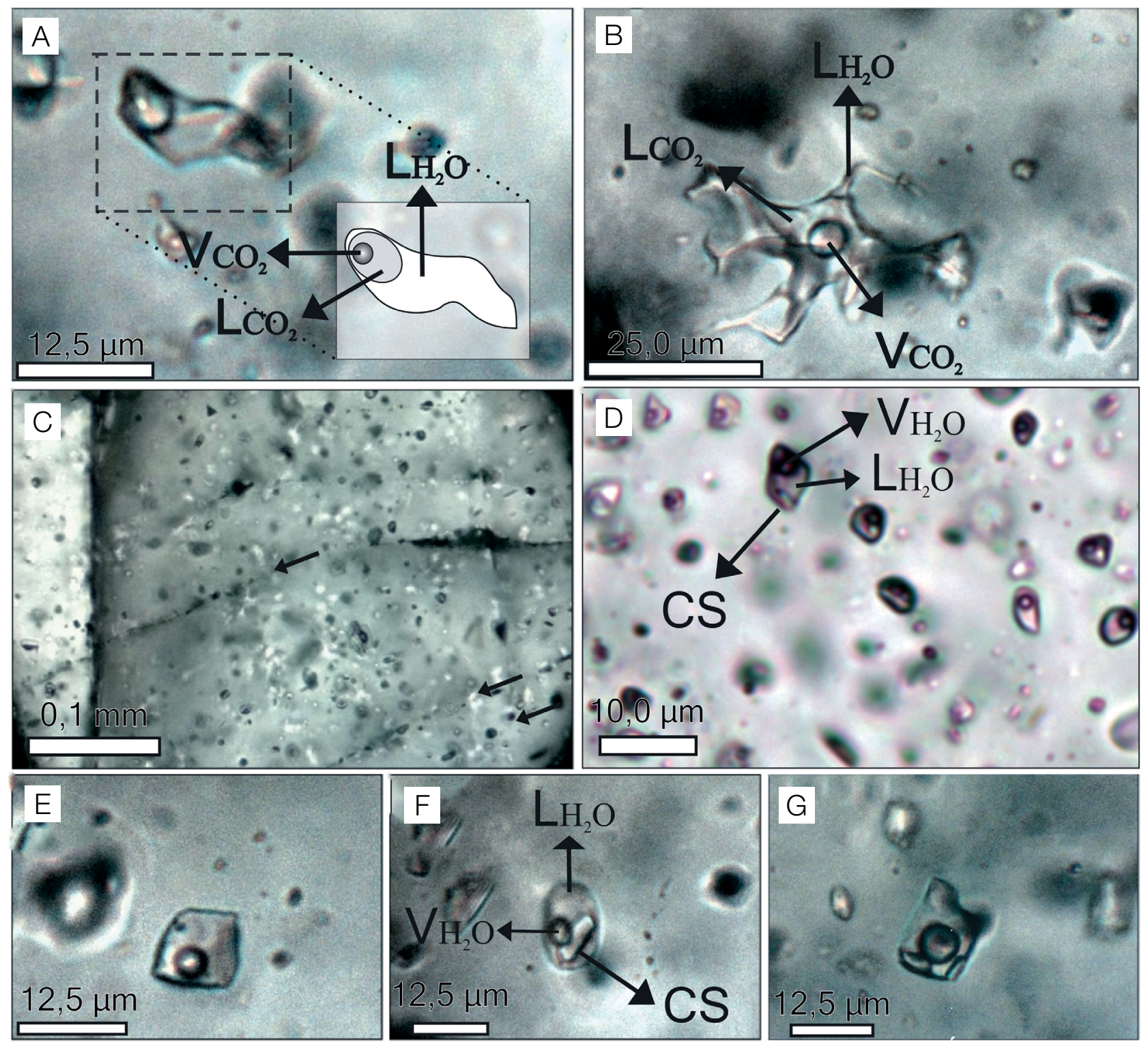

Figura 5. Inclusões fluidas provenientes de veios mineralizados: (A) inclusão primária do tipo I, subangular, e com aproximadamente $20 \%$ de preenchimento pela fase de vapor $\left(\mathrm{V}_{\mathrm{CO}_{2}}\right)$; $(\mathrm{B})$ inclusão do Tipo I com textura de estrangulamento (necking down) e alta porcentagem ( 90\%) da fase de vapor $\left(\mathrm{V}_{\mathrm{CO}}\right)$; (C) inclusões dos tipos II e III distribuídas em formas de nuvens e trilhas secundárias (setas); (D) coexistência entre as inclusões dos tipos II e III; (E-G) heterogeneidade quanto ao tamanho, forma e quantidade dos cristais sólidos observados nas inclusões do Tipo III. Observar a variação no tamanho e hábito do cristal de saturação (S) das inclusões do Tipo III 
representados por inclusões do Tipo II e, em menor proporção, do Tipo III. De modo geral, ambos os grupos são coexistentes nos cristais hospedeiros de quartzo.

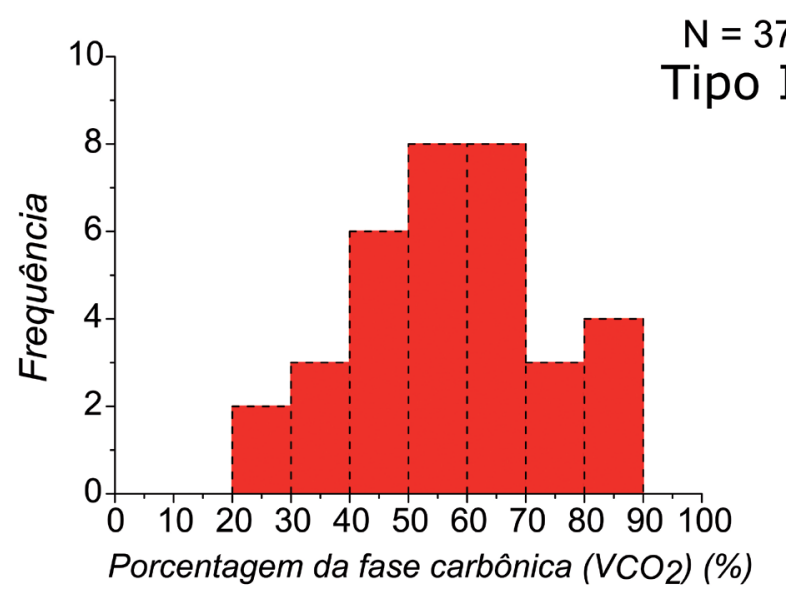

Figura 6. Distribuição heterogênea da porcentagem da fase carbônica $\left(\mathrm{V}_{\mathrm{CO}}\right)$ em relação ao volume total das inclusões fluidas do Tipo I provenientes de veios mineralizados.
As IFs do Tipo I não foram observadas nesse sistema de veios. As do Tipo II ocorrem principalmente em densos arranjos planares (Figura 7A) e subordinadamente como trilhas pseudossecundárias, acompanhando o crescimento do quartzo, ou individualmente isoladas (Figura 7B). Exibem constante e baixa porcentagem da fase vapor em relação ao volume total da IF $(\sim 15 \%)$ (Figura 7C), homogeneidade em suas dimensões $(\sim 25,0$ $\mu \mathrm{m})$, com raros casos que excedem os $50,0 \mu \mathrm{m}$, porém são heterogêneas quanto à forma (hexagonais a subarredondadas). Também foram observadas trilhas secundárias de inclusões do Tipo II. As inclusões do Tipo III são primárias, no geral trifásicas, ocorrem como nuvens isoladas (Figura 7B) e, a exemplo do caso anterior, exibem variações quanto à forma (hexagonais a subarredondadas) e homogeneidade na dimensão $(\sim 25,0 \mu \mathrm{m})$, na porcentagem da fase de vapor $(\sim 25 \%)$ e quanto ao cristal de saturação $(\sim 5 \%)$. A fase sólida possivelmente corresponde à halita, em decorrência de seu hábito cúbico e da similaridade entre o seu índice de refração e o do cristal de quartzo hospedeiro da inclusão (Figura 7D).
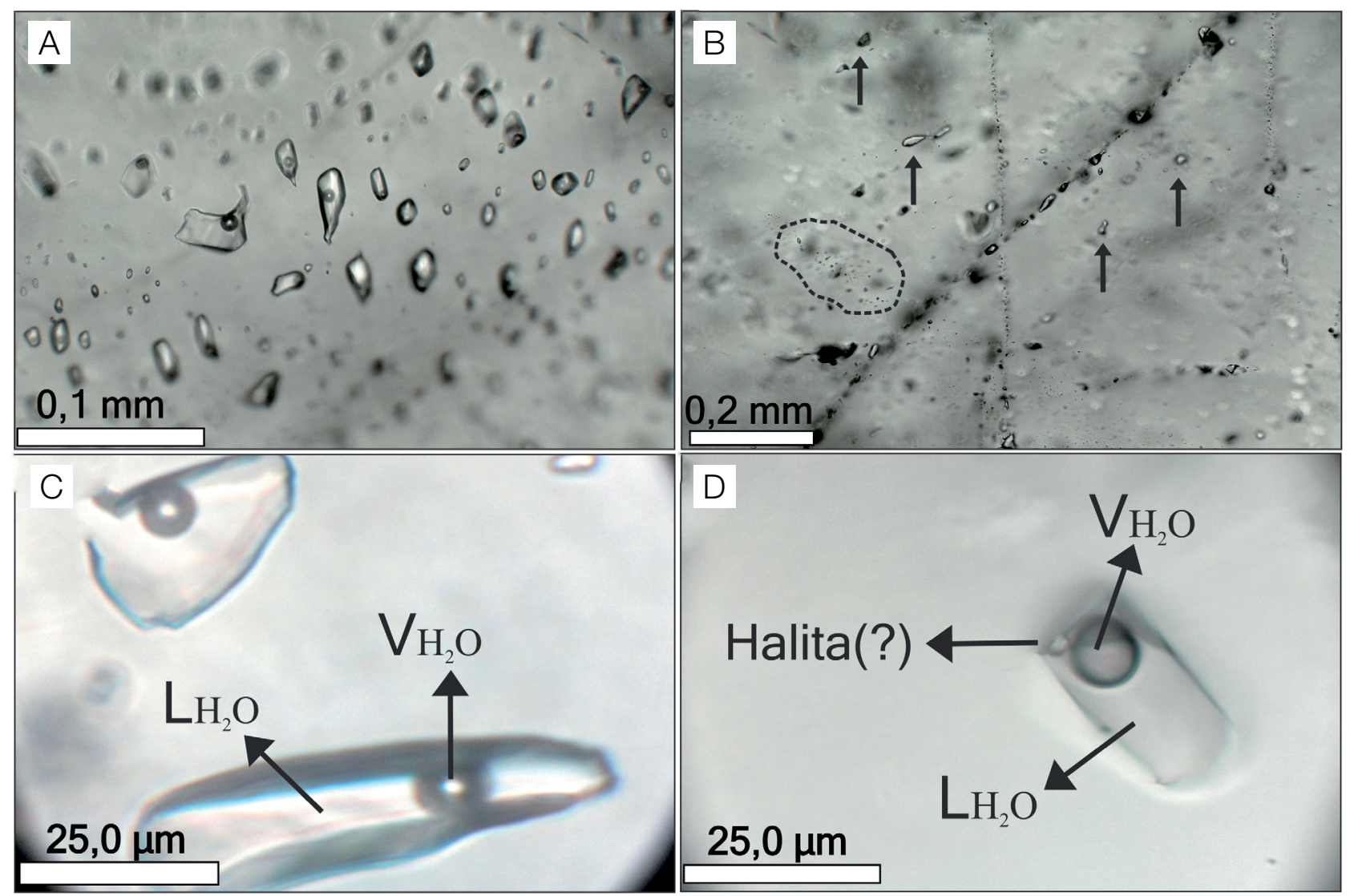

Figura 7. Inclusões fluidas em cristais de quartzo provenientes de veios estéreis: (A) inclusões fluidas do Tipo II distribuídas em arranjo planar; (B) nuvem de inclusões fluidas do Tipo III (linha tracejada) coexistentes com inclusões primárias do Tipo II (setas). Adicionalmente, inclusões secundárias, dispostas em fraturas cicatrizadas (extracristais) também podem ser observadas; (C) inclusões do Tipo II, com baixa porcentagem ( 15\%) da fase vapor $\left(V_{\mathrm{H}_{2} \mathrm{O}}\right)$; (D) Inclusão aquosa trifásica (Tipo III) com pequeno cristal de saturação (halita?). 


\section{MICROTERMOMETRIA}

Os dados microtermométricos referentes às IFs do garimpo do Papagaio encontram-se sumarizados na Tabela 2.

\section{Veios mineralizados}

A temperatura de fusão da fase carbônica $\left(\mathrm{Tf}_{\mathrm{CO}}\right)$ das inclusões do Tipo I apresentou uma moda em $-56,6^{\circ} \mathrm{C}$ com pequena variação até $-59,2^{\circ} \mathrm{C}$ (Figura $8 \mathrm{~A}$ ). Essas temperaturas indicam que o $\mathrm{CO}_{2}$ corresponde ao componente volátil dominante. No decorrer do resfriamento desse grupo de inclusões, houve a nucleação de clatrato entre 6,1 e $8,8^{\circ} \mathrm{C}$, sendo representativas, portanto, de baixas salinidades: de 2,4 a 7,2\% em peso equivalente de $\mathrm{NaCl}$ (Figura 8B). A homogeneização do $\mathrm{CO}_{2}$ ocorreu predominantemente para a fase líquida $(86,5 \%$ dos casos), no intervalo de 18,9 a $30,9^{\circ} \mathrm{C}$, com moda em $29,0^{\circ} \mathrm{C}$ (Figura $8 \mathrm{C}$ ). Essa tipologia de inclusões apresentou crepitação, relativamente homogênea, a partir dos $325^{\circ} \mathrm{C}$ e

Tabela 2. Resumo dos dados microtermométricos para os diferentes tipos de inclusões fluidas provenientes dos veios estéreis e mineralizados do garimpo do Papagaio.

\begin{tabular}{|c|c|c|c|c|c|}
\hline & \multicolumn{3}{|c|}{ Veios mineralizados } & \multicolumn{2}{|c|}{ Veios estéreis } \\
\hline & Tipo I & Tipo II & Tipo III & Tipo II & Tipo II \\
\hline \multicolumn{6}{|l|}{$\mathrm{Te}\left({ }^{\circ} \mathrm{C}\right)$} \\
\hline Min. & - & $-68,2$ & $-64,9$ & $-77,4$ & $-63,8$ \\
\hline Max. & - & $-20,4$ & $-28,3$ & $-70,6$ & $-41,4$ \\
\hline \multicolumn{6}{|l|}{$\operatorname{Tfg}\left({ }^{\circ} \mathrm{C}\right)$} \\
\hline Min. & - & $-22,5$ & - & $-32,3$ & - \\
\hline Max. & - & 0,0 & - & $-25,7$ & - \\
\hline \multicolumn{6}{|l|}{$\mathrm{TH}\left({ }^{\circ} \mathrm{C}\right)$} \\
\hline Min. & - & 115,1 & - & 135,9 & 323,2 \\
\hline Max. & - & 216,2 & - & 190,3 & 402,9 \\
\hline \multicolumn{6}{|c|}{$\operatorname{Tdhh}\left({ }^{\circ} \mathrm{C}\right)$} \\
\hline Min. & - & $-28,1$ & $-26,7$ & - & - \\
\hline Max. & - & $-18,2$ & $-24,4$ & - & - \\
\hline \multicolumn{6}{|c|}{$\mathrm{Tf}_{\mathrm{CO} 2}\left({ }^{\circ} \mathrm{C}\right)$} \\
\hline Min. & $-59,3$ & - & - & - & - \\
\hline Max. & $-56,6$ & - & - & - & - \\
\hline \multicolumn{6}{|c|}{$\operatorname{Tdcl}\left({ }^{\circ} \mathrm{C}\right)$} \\
\hline Min. & 6,1 & - & - & - & - \\
\hline Max. & 8,8 & - & - & - & - \\
\hline \multicolumn{6}{|c|}{$\mathrm{TH}_{\mathrm{CO} 2}\left({ }^{\circ} \mathrm{C}\right)$} \\
\hline Min. & 18,9 & - & - & - & - \\
\hline Max. & 30,9 & - & - & - & - \\
\hline \multicolumn{6}{|c|}{ Salinidade (\% em peso eq. $\mathrm{NaCl}$ ) } \\
\hline Min. & 2,4 & 0,5 & - & 26,0 & 40,0 \\
\hline Max. & 7,2 & 24,0 & - & 30,2 & 47,8 \\
\hline
\end{tabular}

Te: temperatura do eutético; Tfg: temperatura de fusão do gelo; $\mathrm{TH}$ : temperatura de homogeneização total; Tdhh: temperatura de dissolução da hidroalita; $\mathrm{Tf}_{\mathrm{Co}}$ : temperatura de fusão do $\mathrm{CO}_{2}$; Tdcl: temperatura de dissolução do clatrato; $\mathrm{TH}_{\mathrm{CO}}$ : temperatura de homogeneização do $\mathrm{CO}_{2}$. anteriormente a sua homogeneização total, impossibilitando, portanto, a obtenção desse parâmetro.

As inclusões do Tipo II exibem dois intervalos principais para as temperaturas do eutético (Te):

(i) entre $-68,2$ e $-58,9^{\circ} \mathrm{C}$;

(ii) mais representativo ( $89,5 \%$ dos casos), entre $-43,5$ e $-20,4^{\circ} \mathrm{C}$, com moda em $-35,0^{\circ} \mathrm{C}$ (Figura $8 \mathrm{D}$ ).

Embora não frequente, houve a formação de hidroalita em algumas inclusões do grupo, a qual exibiu temperaturas de dissolução entre $-28,1$ e $-18,2^{\circ} \mathrm{C}$. A temperatura de fusão do gelo (Tfg) oscilou de $-22,5$ a $0^{\circ} \mathrm{C}$, demonstrativa de baixos a elevados valores de salinidade $(0,5<$ salinidade $<24 \%$ em peso equivalente em $\mathrm{NaCl}$; Figura $8 \mathrm{E}$ ). A temperatura de homogeneização total $(\mathrm{TH})$ para esse grupo variou de 115,1 a $216,2^{\circ} \mathrm{C}$ (Figura $8 \mathrm{~F}$ ). De acordo com Davis et al. (1990), as temperaturas encontradas para o ponto eutético e dissolução da hidroalita, nem sempre presente, são sugestivas de composições próximas de um sistema $\mathrm{NaCl}-\mathrm{MgCl}_{2}-\mathrm{H}_{2} \mathrm{O}$, além dos dois intervalos de temperaturas existentes para o ponto eutético, em que as temperaturas mais baixas $\left(-68,2\right.$ e $\left.-58,9^{\circ} \mathrm{C}\right)$ seriam resultado da metaestabilidade deste sistema. Nesse contexto, a variação na $\mathrm{Tfg}\left(-22,5\right.$ a $\left.0^{\circ} \mathrm{C}\right)$ também poderia ser justificada pela metaestabilidade do sistema em função da presença de magnésio.

Não foi possível a obtenção de dados microtermométricos para as inclusões do Tipo III, visto que frequentemente corresponderem a inclusões multifásicas com grande heterogeneidade, tanto na quantidade, quanto nas dimensões dos cristais aprisionados. Essa grande variedade é típica do aprisionamento acidental de fases sólidas contaminantes no fluido mineralizante, o que teria permitido a adesão de cristais à parede da inclusão, ou, então, precipitação na superfície de crescimento do cristal de quartzo hospedeiro com seu posterior aprisionamento na inclusão. Essas características impossibilitam estimativas confiáveis dos parâmetros físico-químicos do fluido, dada sua heterogeneidade e instabilidade.

\section{Veios estéreis}

As IFs do Tipo II dos veios estéreis exibem Te que variam de $-77,4$ a $-70,7^{\circ} \mathrm{C}$, com moda entre $-74,0$ e $-73,0^{\circ} \mathrm{C}$ (Figura 9A). A Tfg está compreendida entre $-32,3$ e $-25,7^{\circ} \mathrm{C}$, sugestiva de fluidos de altas salinidades (de 26 a $30,2 \%$ em peso equivalente em NaCl; Figura 9B). A TH ocorre no intervalo de 135,9 a $190,3^{\circ} \mathrm{C}$, com moda em $150,0^{\circ} \mathrm{C}$ (Figura 9C). As IFs do Tipo III, no entanto, apresentaram Te entre $-63,8$ e $-41,4^{\circ} \mathrm{C}$ (Figura 9D). Essas inclusões exibem homogeneização total a partir da dissolução da fase sólida (halita?). Contudo, observou-se a homogeneização de apenas três inclusões, no intervalo de 323,2 a $402,9^{\circ} \mathrm{C}$. Não foi possível 


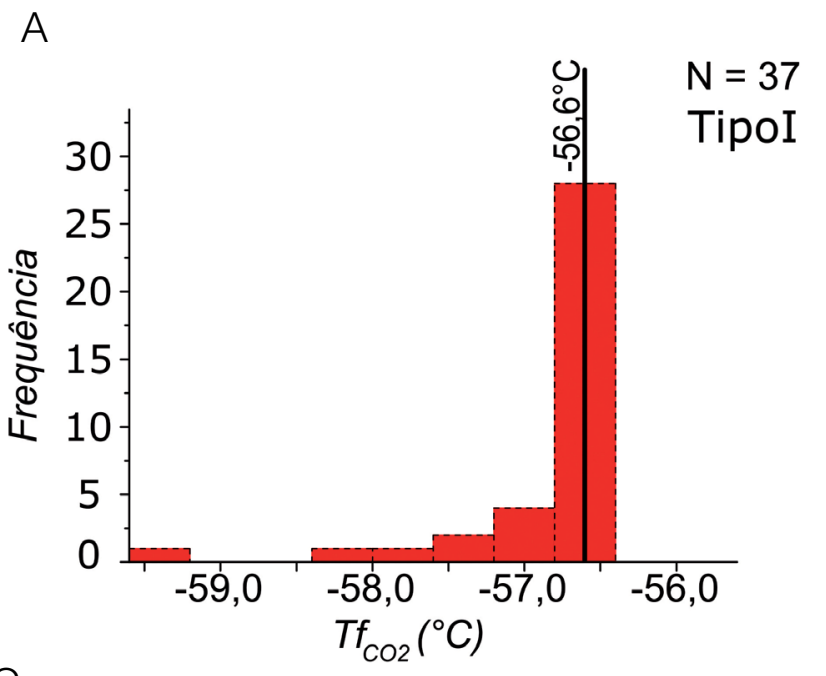

$B$

C
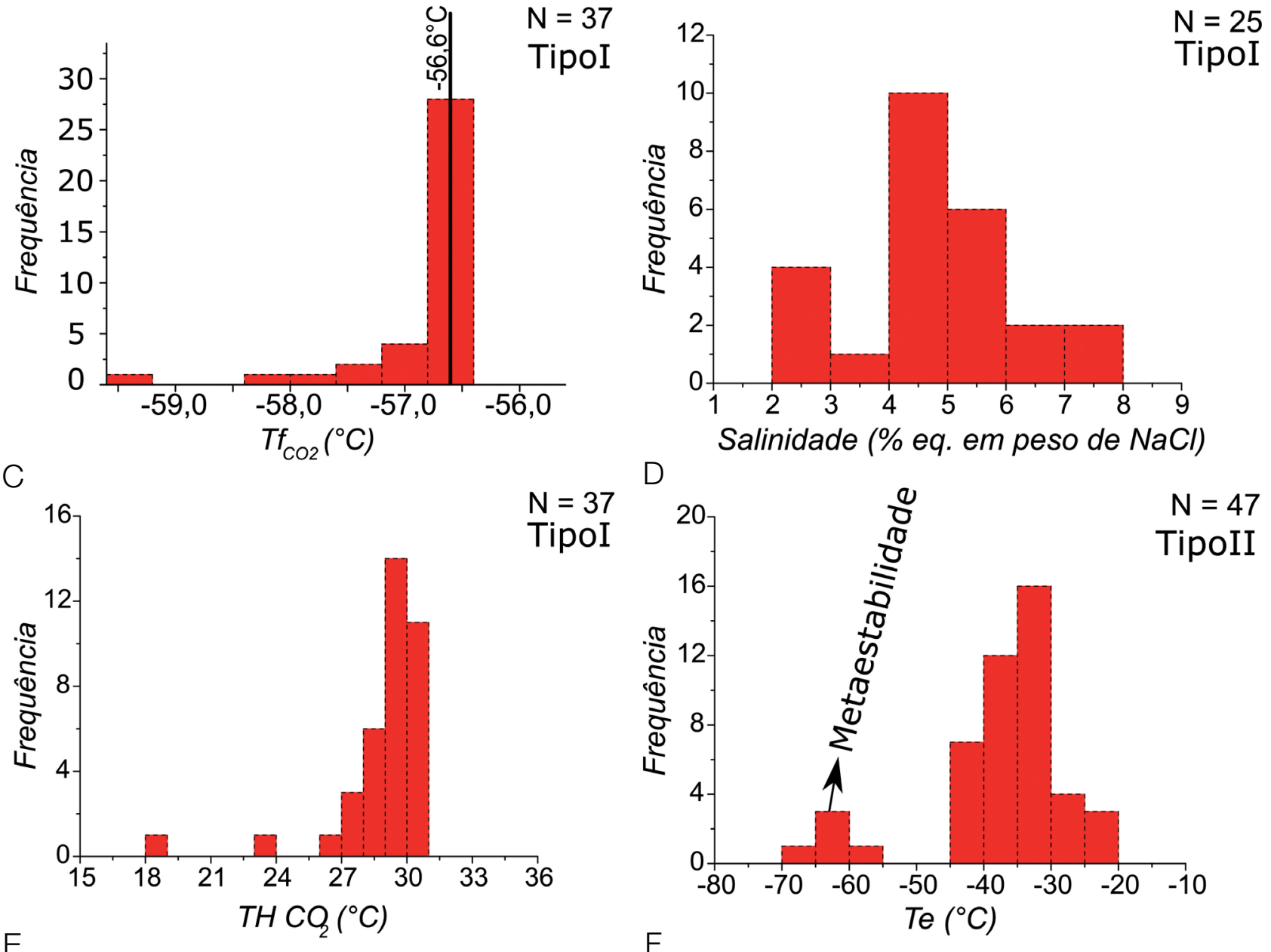

E

$N=37$

TipoI

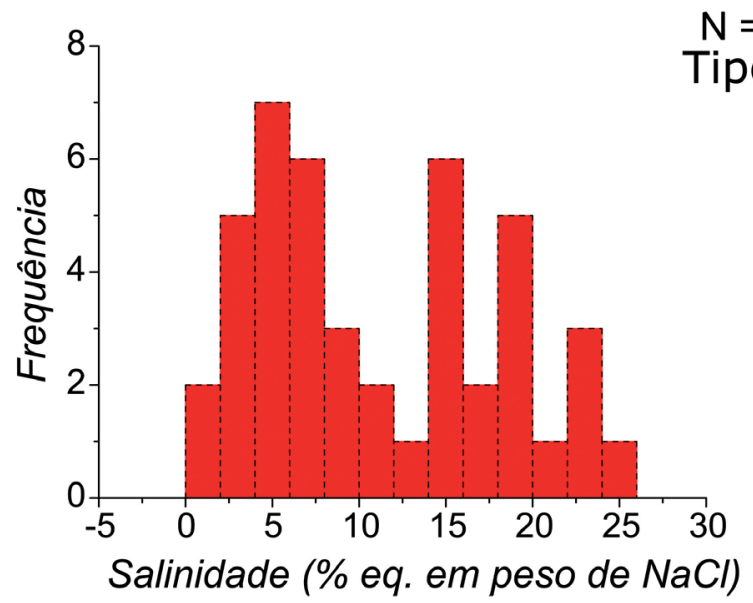

$\mathrm{F}$
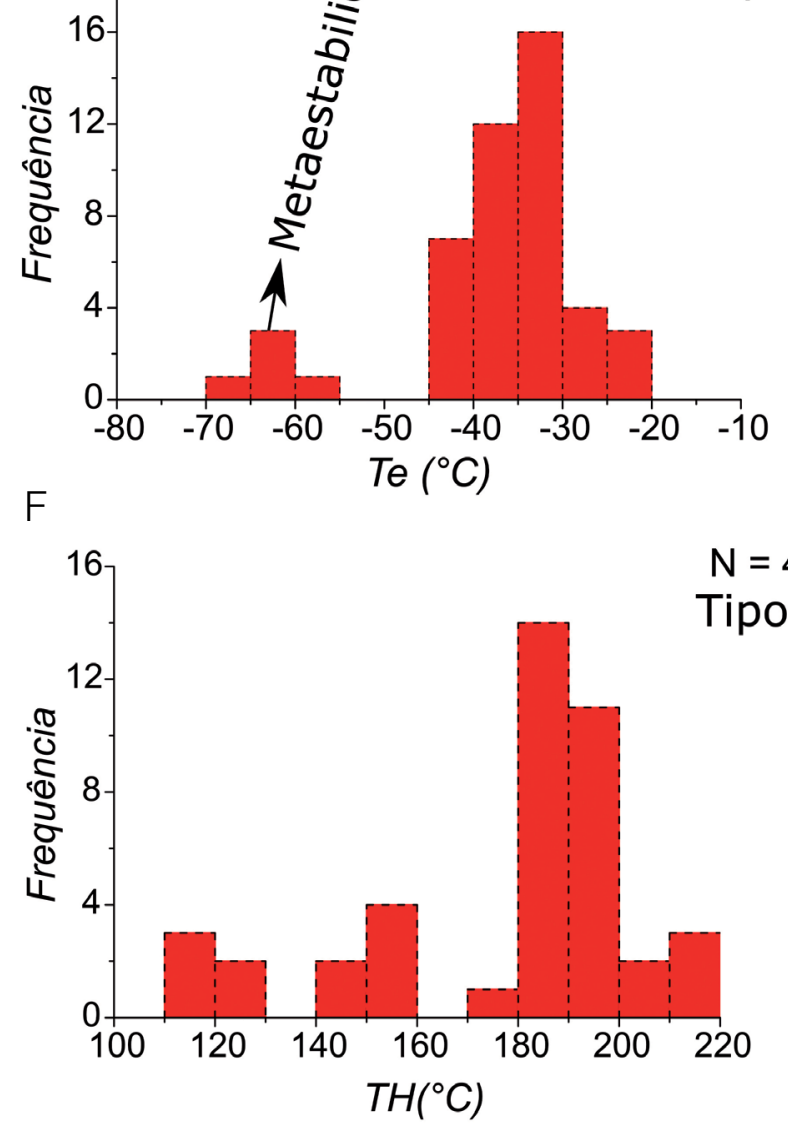

Figura 8. Dispersão dos dados microtermométricos referentes às inclusões fluidas dos tipos I e II observadas nos veios mineralizados: (A) fusão do $\mathrm{CO}_{2}$ das inclusões aquocarbônicas (Tipo I); (B) salinidade das inclusões aquocarbônicas (Tipo I) a partir da fusão do clatrato em inclusões $c o m \mathrm{CO}_{2}$ puro $\left(-56,6^{\circ} \mathrm{C}\right)$; (C) temperatura de homogeneização do $\mathrm{CO}_{2}$ das inclusões do Tipo I; (D) temperaturas do ponto eutético (Te) das inclusões aquosas bifásicas (Tipo II); (E) salinidade das inclusões do Tipo Il a partir das temperaturas de fusão do gelo; (F) temperaturas de homogeneização total (TH) das inclusões aquosas bifásicas (Tipo II). 
a obtenção de maior quantidade de dados pelo fato de as inclusões começarem a crepitar a partir dos $403^{\circ} \mathrm{C}$. Esses resultados indicam, portanto, fluido de elevada salinidade, $(<40 \%$ em peso equivalente em $\mathrm{NaCl})$.

As temperaturas de fusão do gelo $\left(-32,3\right.$ a $\left.-25,7^{\circ} \mathrm{C}\right)$ nas inclusões do Tipo II e eutético do Tipo III $\left(-63,8\right.$ e $\left.-41,4^{\circ} \mathrm{C}\right)$ podem ser justificadas pela presença de $\mathrm{CaCl}_{2}$ e/ou $\mathrm{MgCl}_{2}$ no sistema hidrotermal. Desse modo, as temperaturas encontradas para o eutético das inclusões do Tipo II (-77,4 a $-70,7^{\circ} \mathrm{C}$ ) seriam decorrentes da metaestabilidade destes sistemas composicionais (Davis et al., 1990; Goldstein e Reynolds, 1994).

\section{Geotermobarometria das inclusões}

Isócronas construídas a partir do cruzamento de pares de inclusões aquosas bifásicas e aquocarbônicas permitem estimar que os fluidos responsáveis pela formação dos veios mineralizados exibem temperaturas mínimas de aprisionamento entre 315 e $325^{\circ} \mathrm{C}$, correspondentes a pressões de 1,49 a 1,67 kbar (Figura 10A). Entretanto, observa-se que, nos veios estéreis, as temperaturas $\left(152^{\circ} \mathrm{C}<\mathrm{T}<170^{\circ} \mathrm{C}\right)$ e pressões $(<0,48 \mathrm{kbar})$ são inferiores (Figura 10B). Ressalta-se que, para os veios mineralizados, o intervalo mínimo foi definido a partir do cruzamento das isócronas das inclusões analisadas (ponto de intersecção), enquanto o intervalo superior foi obtido a partir da temperatura de crepitação das inclusões aquocarbônicas. $\mathrm{O}$ intervalo superior das inclusões aquosas bifásicas, contudo, foi determinado a partir da maior temperatura de aprisionamento registrada durante a microtermometria desse grupo de inclusões. Esses dados são compatíveis, portanto, com a evolução paragenética do depósito (Tabela 1), uma vez que o minério estaria relacionado aos estágios iniciais do sistema magmático-hidrotermal

$B$
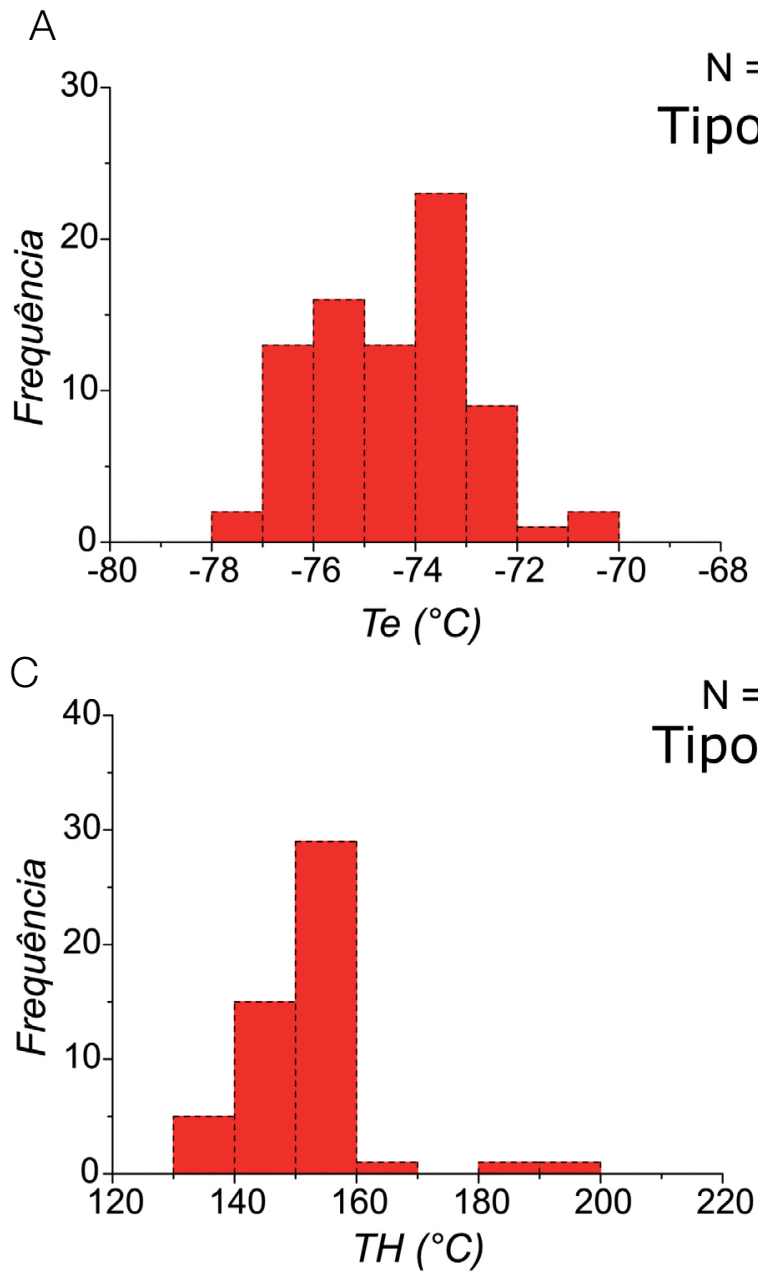
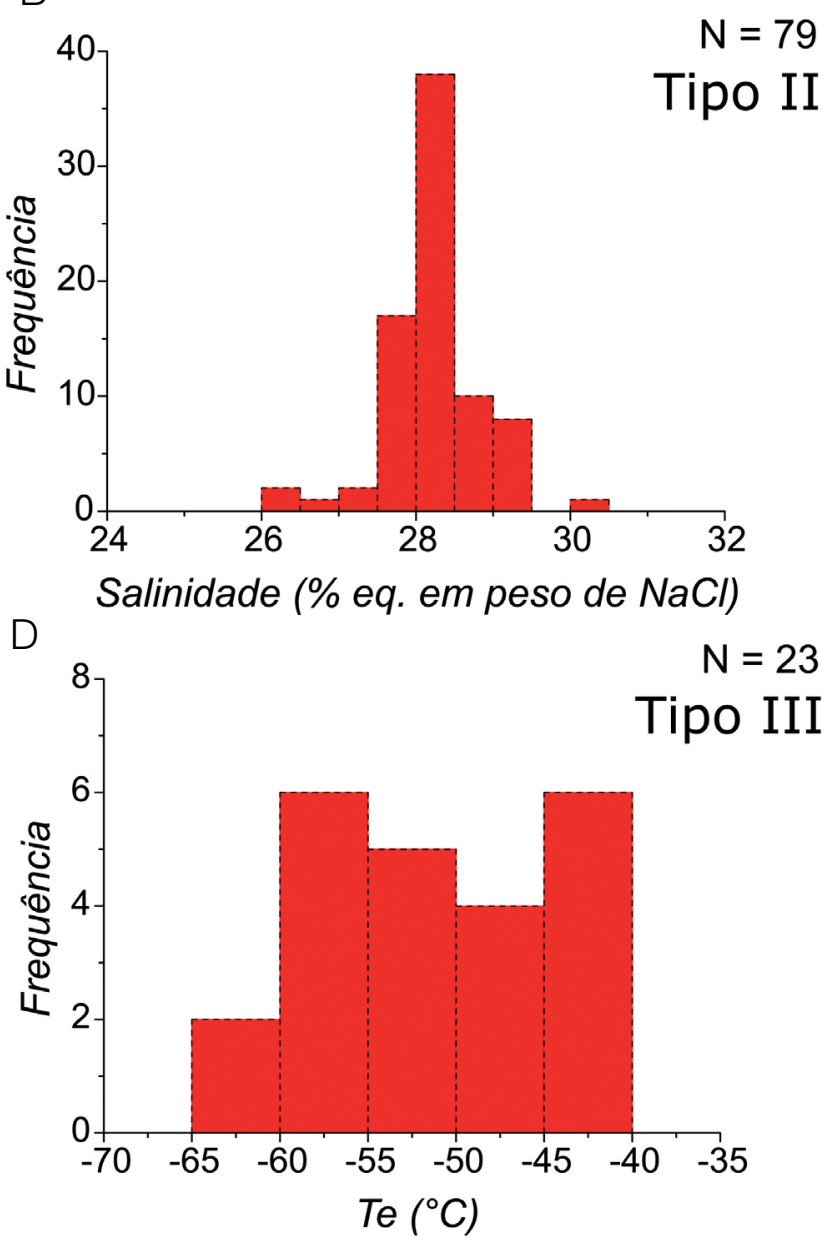

Figura 9. Variação dos dados microtermométricos das inclusões fluidas dos tipos II e III provenientes de veios estéreis do garimpo do Papagaio: (A) temperatura do eutético (Te) das inclusões aquosas bifásicas (Tipo II); (B) salinidade das inclusões do Tipo II; (C) temperatura de homogeneização total (TH) das inclusões do Tipo II; (D) variação da temperatura do ponto eutético (Te) das inclusões aquosas trifásicas (Tipo III). 
do garimpo do Papagaio e, portanto, à maiores pressões e temperaturas, enquanto os veios estéreis registram a fase tardia do sistema, em condições mais diluídas e oxidantes.

Neste contexto, o garimpo do Papagaio mostra condições de temperatura similares às observadas para os depósitos auríferos disseminados do Pé Quente e X1, porém, com pressões inferiores (Assis, 2015).

\section{DISCUSSÕES E CONCLUSÕES}

A estreita relação espacial entre os padrões da alteração hidrotermal, das zonas mineralizadas e dos sistemas graníticos de 1781,4 \pm 7,5 Ma do garimpo do Papagaio indica que a precipitação do minério esteve vinculada a um sistema magmático-hidrotermal paleoproterozoico.

A mineralização ocorre hospedada em dacito porfirítico de afinidade calcioalcalina de médio a alto $\mathrm{K}$, posicionado em ambiente pós-orogênico (Galé et al., 2015). As fases acessórias observadas na rocha hospedeira (e.g., magnetita e anfibólio) são típicas de granitos hidratados e oxidados (granitos tipo I, série da magnetita). No conjunto, esses dados são semelhantes aos de rochas hospedeiras descritas em sistemas do tipo $\mathrm{Cu} \pm$ Au pórfiro e Au pórfiro (Sillitoe, 2010; Seedorff et al., 2005; Sinclair, 2007; Taylor, 2007; Sun et al., 2015).

No contexto da província, os estilos e as tipologias da alteração hidrotermal (e.g., alterações potássica, sericítica e propilítica) observados no depósito do Papagaio são similares aos estudados no segmento leste da PAAF, a exemplo dos do Francisco (Assis, 2011), Luizão (Paes de Barros, 2007), Pombo (Biondi et al., 2006, 2007; Biondi, 2009),
Serrinha (Moura et al., 2006), Pé Quente (Assis, 2011), Trairão (Dias, 2012), X1 (Rodrigues, 2012) e Juruena (Serrato, 2014), este último situado em seu setor oeste. $\mathrm{O}$ zoneamento da alteração hidrotermal foi iniciado pela alteração potássica, que evoluiu para serícitica quando mais proximal ao minério e foi, por sua vez, parcialmente sobreposta pela propilítica de cunho mais regional. Esse padrão de distribuição das zonas de alteração hidrotermal é semelhante ao descrito para os inúmeros depósitos do leste da província (Assis et al., 2014). Entretanto, não foi constatada alteração sódica no garimpo do Papagaio, tal como reconhecida nos depósitos do Edu (Silva e Abram, 2008) e do Pé Quente (Assis, 2011).

O estudo de IFs revela que os veios mineralizados exibem regime de fluidos distinto do observado nos veios estéreis. Nos veios sulfetados, três tipos de inclusões foram encontradas:

(i) aquocarbônicas;

(ii) aquosas bifásicas;

(iii) aquosas salinas trifásicas.

Os fluidos aquocarbônicos (Tipo I) são primários, de alta temperatura $\left(>325^{\circ} \mathrm{C}\right)$ e baixa salinidade $(2,4$ a $7,2 \%$ em peso equivalente em $\mathrm{NaCl}$ ). Remetem a IFs com grande variação na porcentagem do $\mathrm{CO}_{2}$ em relação ao volume total da inclusão e que apresentaram temperaturas de crepitação relativamente homogêneas $\left(\sim 330^{\circ} \mathrm{C}\right)$, indicativas de processos de imiscibilidade de fluidos em nível crustal profundo, na transição do ambiente hipotermal ao mesotermal (> $5 \mathrm{~km}$ ) (Bakker e Jansen, 1991; Baker, 2002), visto a solubilidade do $\mathrm{CO}_{2}$ ser diretamente proporcional ao aumento de pressão e alcalinidade do
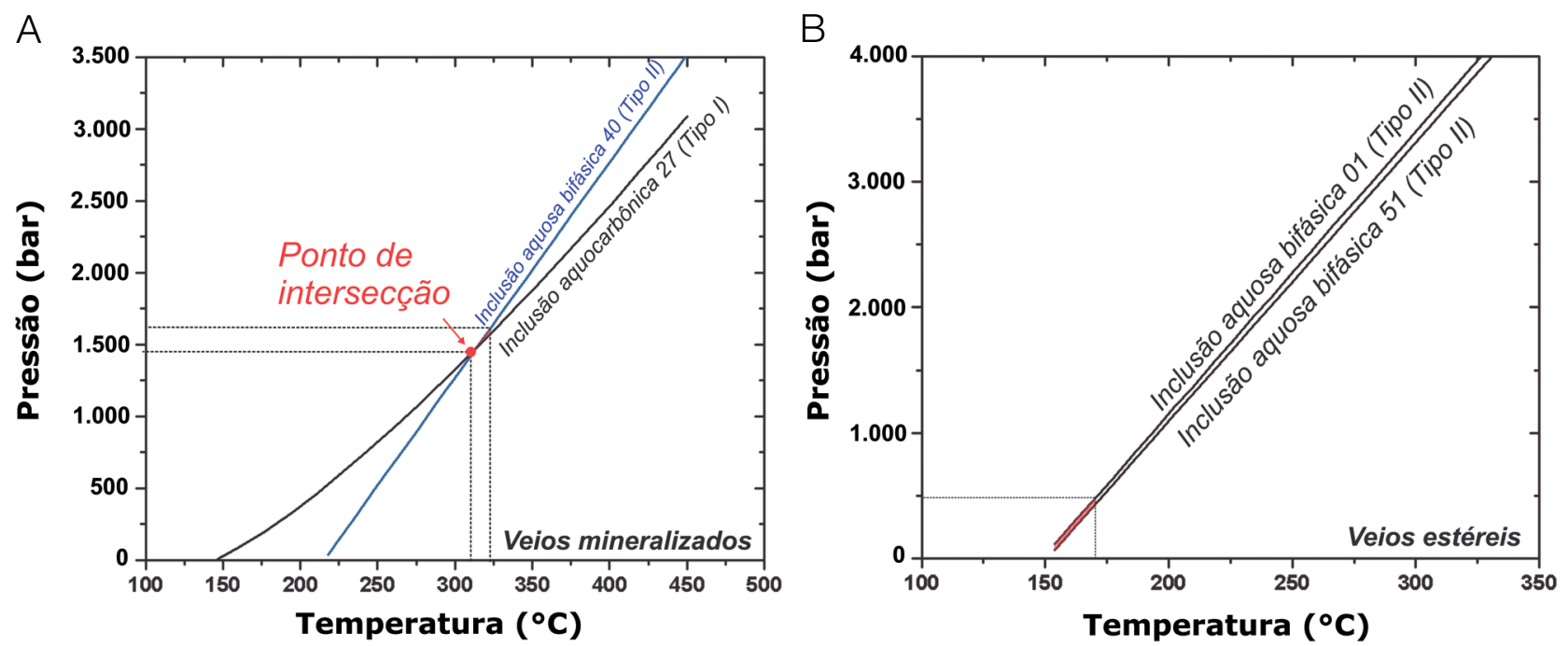

Figura 10. Diagramas de pressão versus temperatura calculados a partir de Bakker (2003). (A) Veios mineralizados com temperaturas entre 315 e $325^{\circ} \mathrm{C}$ e pressões de 1,49 a $1,67 \mathrm{kbar}$; (B) veios estéreis com temperaturas entre 152 e $170^{\circ} \mathrm{C}$ e pressões abaixo de 0,48 kbar. 
magma (Lowenstern, 2001). Uma vez que as hospedeiras graníticas do garimpo do Papagaio exibem afinidade geoquímica calcioalcalina de alto K (Galé et al., 2015), sugere-se que oscilações do nível crustal devam ter sido mais eficientes e determinantes na solubilidade do $\mathrm{CO}_{2}$ dentro da câmera magmática do que controles geoquímicos do magma, pois fluidos exsolvidos em profundidade na crosta exibem altas razões $\mathrm{CO}_{2} / \mathrm{H}_{2} \mathrm{O}$ quando comparados àqueles derivados de sistemas próximos à superfície (Lowenstern, 2001).

Os fluidos aquosos (Tipo II) são de menor temperatura $\left(115,1\right.$ a $\left.216,2^{\circ} \mathrm{C}\right)$ e maior salinidade $(\sim 0,5 \mathrm{a} \sim 24,0 \%)$ em relação aos fluidos aquocarbônicos. A ausência de estruturas de estrangulamento das inclusões (necking down), somada à perda de $\mathrm{CO}_{2}$, ao decréscimo de temperatura e ao aumento da salinidade, é um indicativo de que este fluido é mais novo e não tão profundo em relação ao anterior. Entretanto, a ausência de evidência de boiling pode estar associada a pressões ainda significativas, o que descarta um ambiente muito raso (epitermal) para este fluido. Nesse contexto, os fluidos aquosos poderiam ser provenientes da cristalização de magmas em ambiente subvulcânico (Baker, 2002) decorrente da mudança no nível crustal e da ascensão da câmara magmática. A diminuição de $\mathrm{CO}_{2}$ e o aumento de salinidade do sistema hidrotermal implicariam o aumento da acidez dos fluidos, o que poderia estar relacionado à geração da alteração sericítica.

Os fluidos aquosos trifásicos (Tipo III) apresentam heterogeneidade tanto no tamanho quanto na quantidade de cristais inclusos (IFs tri a multifásicas), o que indica corresponderem a sólidos acidentalmente capturados em regime heterogêneo de fluidos. Esse fato inviabilizou a utilização de seus dados microtermométricos, por corresponderem a fluidos em sistema não estável. Entretanto, mesmo com salinidades e temperaturas desconhecidas, sugere-se tratar de um fluido aquoso e tardio, pois o aprisionamento acidental dos cristais seria resultado da perda da solubilidade de determinados elementos, decorrente de um ambiente com menor pressão e temperatura (epitermal?) em relação ao anterior. Uma possível mistura com fluidos de origem indefinida (meteórica?) também poderia ter contribuído para a perda de temperatura e a diluição dos fluidos no sistema hidrotermal, inclusive favorecendo a formação da alteração propilítica.

As IFs dos veios mineralizados foram aprisionadas em maiores temperaturas e pressões do que as dos veios estéreis, indício de que a precipitação do minério poderia estar associada a uma fase precoce e mais profunda do sistema magmático-hidrotermal. Este contexto condiz com a ausência de evidências do registro de boling nas inclusões aquosas dos veios mineralizados, o que, de acordo com
Baker (2002), é uma característica de ambientes profundos $(>5 \mathrm{~km})$. Dessa forma, os fluidos responsáveis pela formação de veios estéreis possivelmente migraram em regime mais raso e em estágio tardio em relação aos mineralizantes e, portanto, teriam sido aprisionados posteriormente, após o colapso do sistema hidrotermal metalífero.

Nesse contexto, o processo de desgaseificação de $\mathrm{CO}_{2}$ pode ter provocado mudanças nas condições físico-químicas e, consequentemente, a precipitação do conteúdo metalífero do garimpo do Papagaio. Isso pode ser decorrente da variação do nível crustal durante a colocação do corpo magmático que, de acordo com Baker (2002), pode ter variado inicialmente de 7 a $5 \mathrm{~km}$. É nessas profundidades que ocorre a mudança no estado de solubilidade do $\mathrm{CO}_{2}$, o que também justifica a formação dos fluidos aquosos posteriores. Os dados de TH versus salinidade para cada um dos tipos de fluido são expressos na Figura 11.

Microinclusões de calcopirita em cristais de esfalerita (chalcopyrite disease) da zona mineralizada indicam que o minério pode ter se precipitado em temperaturas entre 200 e $400^{\circ} \mathrm{C}$ (Nagase e Kojima, 1997), coerentes, portanto, com os dados obtidos pelas IFs.

Os veios estéreis, por sua vez, são tardios em relação aos mineralizados, e dominantemente representados por um regime de fluidos salinos (Figura 10), possivelmente derivados da interação entre fluidos aquosos bifásicos de baixa temperatura e aquosos trifásicos de alta temperatura. Neste cenário, fluidos trifásicos hipersalinos $(40-47,7 \%$ em peso equivalente em $\mathrm{NaCl}$ ) de elevada temperatura

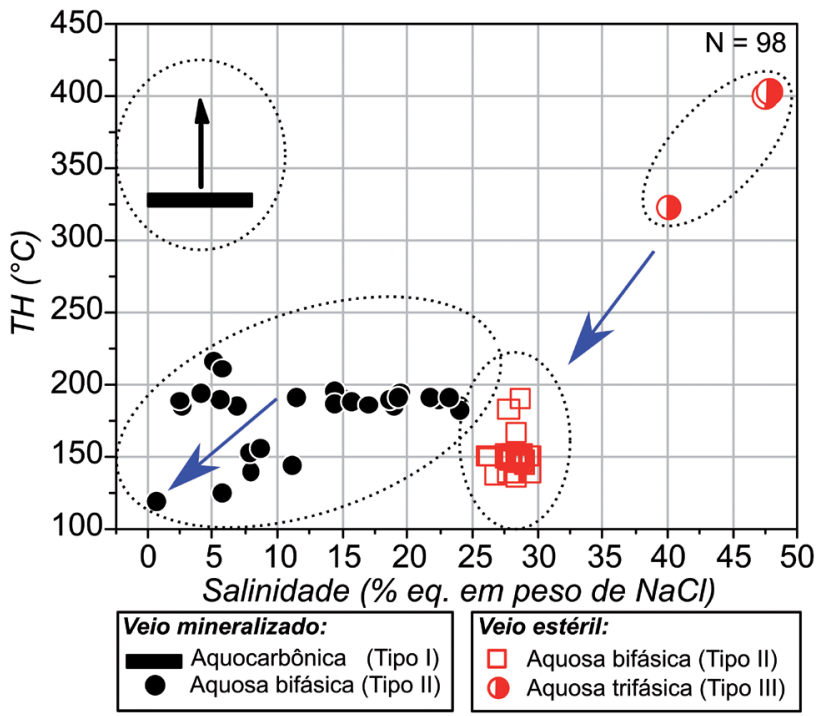

Figura 11. Correlaçãoentretemperatura dehomogeneização total (TH) das inclusões e salinidade (\% peso equivalente em $\mathrm{NaCl}$ ) para as inclusões descritas nos veios mineralizados e estéreis do garimpo do Papagaio. As setas azuis indicam provável interação com fluidos externos. 
$\left(323-402^{\circ} \mathrm{C}\right)$, representados pelas inclusões Tipo III, provavelmente originados a partir da exsolução de fluidos magmáticos, teriam interagido com fluidos aquosos salinos $(26-30 \%$ em peso equivalente em $\mathrm{NaCl})$ de menor temperatura $\left(135-190^{\circ} \mathrm{C}\right)$ (inclusões do Tipo II) e de origem ígnea ou sedimentar. Portanto, esse regime de fluidos pode estar relacionado a um pulso mais tardio em relação ao evento hidrotermal mineralizante.

Coletivamente, a ocorrência de fluidos aquocarbônicos de origem primária e aquosos bifásicos, as correlações entre temperaturas de homogeneização total e salinidades são indicativas de que um paleossistema magmático-hidrotermal teria sido o responsável pela gênese do garimpo aurífero do Papagaio. Nesse contexto, um sistema em imiscibilidade teria exsolvido fluidos ricos em $\mathrm{CO}_{2}$ (processo de desgaseificação magmática) e promovido a precipitação do minério. Posteriormente, fluidos aquosos magmáticos teriam interagido com fluidos externos, mais frios e oxidantes (meteóricos?), o que teria culminado no rebaixamento da temperatura do sistema. Os fluidos estéreis, igualmente de origem magmática, são mais novos e também teriam interagido com fluidos externos mais frios. O modelo evolutivo do paleossistema hidrotermal do garimpo do Papagaio pode ser observado na Figura 12.

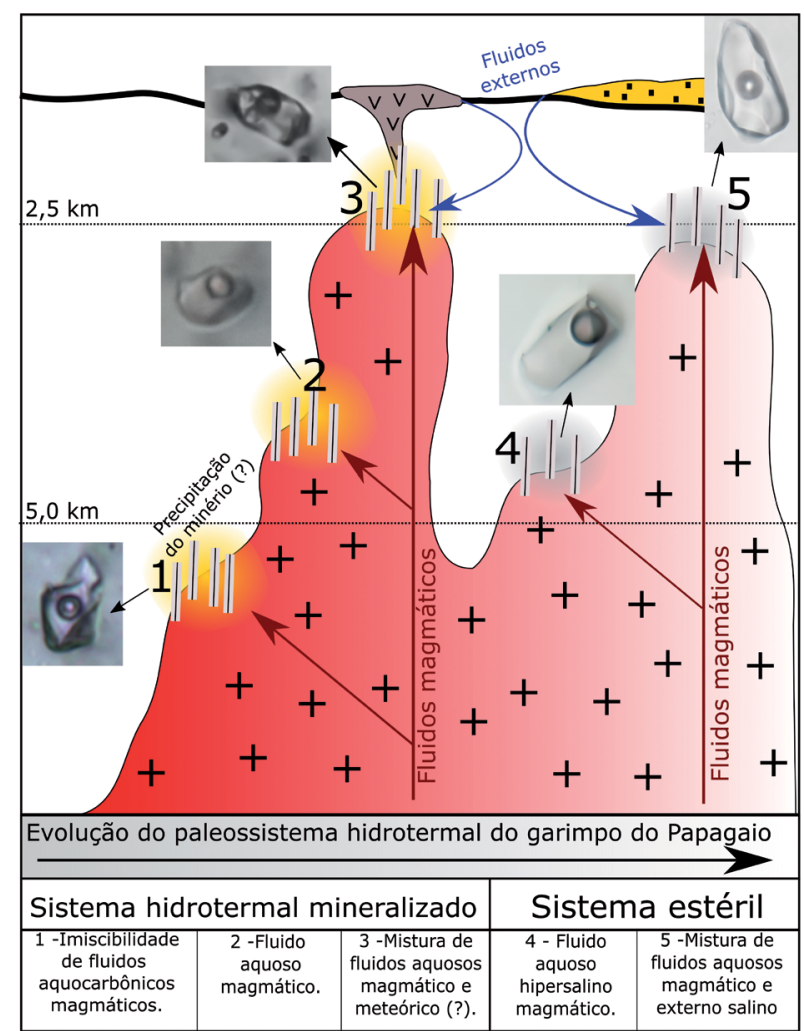

Figura 12. Modelo evolutivo do paleossistema hidrotermal do garimpo do Papagaio.
Estruturas deformacionais descritas anteriormente na região (Silva e Abram, 2008; Quaresma e Hatanaka, 2011) são encontradas apenas localmente nas rochas hospedeiras da mineralização, e registros de uma deformação regional não são evidentes. Entretanto, estruturas como stockworks e brechas hidrotermais, que caracterizam um ambiente raso sem compressão significativa no momento de instalação do sistema hidrotermal, são facilmente encontradas em toda a zona mineralizada do garimpo. Deste modo pode-se concluir que a deformação progressiva existente na região não afetou significativamente as rochas do depósito tampouco teria colaborado como fonte de fluidos para a mineralização, visto que a concordância do sentido dos veios com as estruturas regionais seria decorrente de planos de fraqueza das rochas, que canalizou os fluidos mineralizantes em uma direção preferencial.

A existência de fluidos aquocarbônicos de alta temperatura e baixa salinidade e de fluidos aquosos bifásicos de temperaturas e salinidades variadas indica que a saturação de fluidos por parte da hospedeira deve ter ocasionado fraturamento hidráulico das encaixantes (rebaixamento da pressão), as quais promoveram a liberação de soluções magmáticas e consequente interação com fluidos externos, a níveis crustais mais rasos, o qual estaria ilustrado pelas brechas hidráulicas. Todas essas características são, portanto, similares àquelas descritas para depósitos profundos gerados em arco magmático, como sistemas do tipo pórfiro, a exemplo das reportadas por Sinclair (2007); Taylor (2007); Sillitoe (2010), Pirajno (1992, 2009) e Sun et al. (2015) ou mesmo intrusion-related gold systems (IRGS) (e.g., Hart e Goldfarb, 2005; Hart, 2005, 2007). De acordo com a profundidade da fonte dos fluidos e da preservação do nível crustal, sistemas magmático-hidrotermais semelhantes (e.g., pórfiros de $\mathrm{Au} \pm \mathrm{Cu}$, epitermal high- intermediate e low sulfidation) vêm sendo sugeridos para as mineralizações associadas ao magmatismo ácido no sul do Cráton Amazônico (Juliani et al., 2005; Paes de Barros, 2007; Xavier et al., 2011; Assis et al., 2014; Assis, 2015; Bettencourt et al., 2016).

Por fim, as seguintes características podem ser sumarizadas quanto às zonas mineralizadas do garimpo do Papagaio:

(i) íntima relação genética e espacial com sistemas magmáticos oxidados do tipo I que se desenvolveram em ambiente de margem continental ativa;

(ii) zoneamento da alteração hidrotermal, com relativa extensão dos estilos;

(iii) zonas mineralizadas originadas a partir da interação entre fluidos aquocarbônicos e aquosos bifásicos;

(iv) fluidos com conteúdo metalífero provenientes de ambiente profundo, mesotermal.

Neste contexto, a colocação de corpos subvulcânicos na PAAF tem sido reportada como essencial na gênese de suas 
mineralizações auríferas. Assis et al. (2017) e Assis (2015) reportam idades Re-Os em pirita e molibdenita de $1785 \pm 1$ Ma para os depósitos auríferos disseminados do setor leste da província, assim como idades ${ }^{40} \mathrm{Ar} /{ }^{39} \mathrm{Ar}$ de $1779 \pm 6 \mathrm{a}$ $1777 \pm 6$ em sericita do sistema epitermal low sulfidation do Francisco. Observa-se, portanto, que esses dados se mantêm similares e compatíveis aos aqui reportados, inseridos no segmento noroeste da província, a exemplo da idade $\mathrm{U}-\mathrm{Pb}$ de cristalização de 1781,4 \pm 7,5 Ma obtida para o dacito hospedeiro. Neste cenário, essas evidências reforçam a hipótese de que a colocação de corpos subvulcânicos de idade 1,78 $1,77 \mathrm{Ga}$, possivelmente correlacionados ao grupo Colíder, teria sido responsável pela metalogênese do ouro na PAAF.

\section{AGRADECIMENTOS}

Os autores agradecem ao Professor Dr. Roberto Perez Xavier e ao IG-UNICAMP o auxílio na aquisição e interpretação de dados de IFs. Também agradecem à Coordenação de Aperfeiçoamento de Pessoal de Nível Superior (CAPES), PROCAD 68/2010 n. 23038.000675/2010-15, CT-Mineral/MCT/CNPq (Proc.: 550342/2011-7), ao Instituto Nacional de Ciência e Tecnologia de Geociências da Amazônia(INCT-Geociam) (Proc.: 573733/20082) $-\mathrm{MCT} / \mathrm{CNPq} / \mathrm{FAPESPA} / \mathrm{PETROBRAS}$, o auxílio financeiro; e à GEOMIN Geologia e Mineração Ltda., o auxílio no acesso ao campo e doação das amostras de testemunho e também, aos revisores, com suas importantes contribuições.

\section{REFERÊNCIAS}

Assis, R. R. (2011). Depósitos auriferos associados ao magmatismo granítico do setor leste da Província de Alta Floresta (MT), Cráton Amazônico: tipologia das mineralizações, modelos genéticos e implicações prospectivas. Dissertação (Mestrado). Campinas: Instituto de Geociências, Unicamp. 428p.

Assis, R. R. (2015). Depósitos auriferos associados ao magmatismo félsico da Província de Alta Floresta (MT), Cráton Amazônico: litogeoquímica, idade das mineralizações e fonte dos fluidos. Tese (Doutorado). Campinas: Instituto de Geociências, Unicamp. 363p.

Assis, R. R., Xavier, R. P., Creaser, R. (2017). Linking the timing of disseminated granite-hosted gold-rich deposits to Paleoproterozoic felsic magmatism at Alta Floresta Gold Province, Amazon Craton, Brazil: insights from pyrite and molybdenite Re-Os geochronology. Economic Geology, 112, 1937-1957. DOI: 10.5382/econgeo.2017.4535

Assis, R. R., Xavier, R. P., Paes de Barros, A. J., Barbuena, D., Trevisan, V. G., Ramos, G., Teixeira, R. V., Miguel-Jr.,
E., Rodrigues, R. M., Stabile, A., Santos, T. J. S., Miranda, G. M. T., Barros, M. A. S., Pinho, F. E. C. (2014). Metalogênese do setor leste da Província de Alta Floresta (MT), Cráton Amazônico. In: M. G. S. Silva, M. B. Rocha Neto, H. Jost, R. M. Kuyumjian (Eds.), Metalogênese das Províncias Tectônicas Brasileiras (v. 1, 305-340). Belo Horizonte: CPRM - Serviço Geológico do Brasil.

Baker, T. (2002). Emplacement depth and carbon dioxiderich fluid inclusions in intrusion-related gold deposits. Economic Geology, 97, 1111-1117. https://doi.org/10.2113/ gsecongeo.97.5.1111

Bakker, R. J. (2003). Package FLUIDS 1. Computer programs for analysis of fluid inclusion data and for modelling bulk fluid properties. Chemical Geology, 194, 3-23. https://doi.org/10.1016/ S0009-2541(02)00268-1

Bakker, R. J., Jansen, B. H. (1991). Experimental post-entrapment water loss from synthetic $\mathrm{CO}_{2}-\mathrm{H}_{2} \mathrm{O}$ inclusions in natural quartz. Geochimica et Cosmochimica Acta, 55, 2215-2230. https://doi. org/10.1016/0016-7037(91)90098-P

Barros, M. A. S., Chemale Jr., F., Nardi, L. V. S., Lima, E. F. (2009). Paleoproterozoic bimodal post-collisional magmatism in the southwestern Amazonian Craton, Mato Grosso, Brazil: Geochemistry and isotopic evidence. Journal of South American Earth Sciences, 27, 11-23. DOI: 10.1016/j. jsames.2008.11.003

Barton, P. B. Jr., Bethke, P. M. (1987). Chalcopyrite disease in sphalerite: pathology and epidemiology. American Mineralogist, 72, 451-467. DOI: 0003-004x/87/0506-0451\$02.00

Bettencourt, J. S., Juliani, C., Xavier, R. P., Monteiro, L. V. S., Bastos Neto, A. C., Klein, E. L., Assis, R. R., Leite Jr., W. B., Moreto, C. P. N., Fernandes, C. M. D., Pereira, V. P. (2016). Metallogenetic systems associated with granitoid magmatism in the Amazonian Craton: An overview of the present level of understanding and exploration significance. Journal of South American Earth Sciences, 68, 22-49. DOI: 10.1016/j.jsames.2015.11

Biondi, J. C. (2009). Condições de gênese do depósito de $\mathrm{Au}-\mathrm{Cu}$ (Bi) Pombo (Terra Nova do Norte-MT) estimadas com microtermometria de inclusões fluidas e termometria de clorita. Revista Brasileira de Geociências, 39(2), 213-229.

Biondi, J. C., Franke, N. D., Carvalho, P. R., Villanova, S. N. (2006). Mineralogia e química do minério de $\mathrm{Au}-\mathrm{Cu}$ (Bi) do depósito Pombo (Terra Nova do Norte-MT). Revista Brasileira de Geociências, 36(4), 603-622. 
Biondi, J. C., Franke, N. D., Carvalho, P. R., Villanova, S. N. (2007). Petrografia e petroquímica das zonas de alteração hipogênicas do depósito de Au-Cu (Bi) Pombo, Terra Nova do Norte (MT). Revista Brasileira de Geociências, 37(1), 129-147.

Bodnar, R. J. (2003). Introduction to fluid inclusions. In: I. Samson, A. Anderson, D. Marshall (Eds.), Fluid Inclusions: Analysis and interpretation. Quebec: Mineralogical Association of Canada. p.1-8 (Short Course, 32).

Botelho, N. F., Moura, M. A. (1998). Granite-ore deposit relationships in Central Brazil. Journal of South American Earth Sciences, 11(5), 427-438. DOI: 10.1016/S0895-9811(98)00026-1

Carneiro, C. C., Carreiro-Araújo, S., Juliani, C., Crósta, A. P., Monteiro, L. V. S., Fernandes, C. M. D. (2014). Arcabouço crustal da região sul do Cráton Amazonas. Evidências geofísicas e implicações tectônicas. 47 Congresso Brasileiro de Geologia. Salvador: SBG [CD-ROM].

Cordani, U. G., Teixeira, W., D’Agrella, M. S., Trindade, R. I. (2009). The position of the Amazonian Craton in supercontinents. Gondwana Research, 15, 396-407. https://doi.org/10.1016/j.gr.2008.12.005

Dardene, M. A., Schobbenhaus, C. (2001). Metalogênese do Brasil. Brasília: Universidade de Brasília.

Davis, D. W., Lowenstein, T. K., Spencer, R. J. (1990). Melting Behavior of fluid inclusions in laboratory - Grown halite crystals in the systems $\mathrm{NaCl}-\mathrm{H} 2 \mathrm{O}, \mathrm{NaCl}-\mathrm{KCl}-\mathrm{H} 2 \mathrm{O}, \mathrm{NaCl}-\mathrm{MgCl} 2-\mathrm{H} 2 \mathrm{O}$, and NaCl-CaCl2-H2O. Geochimica et Cosmochimica Acta, 54, 591-601. https://doi.org/10.1016/0016-7037(90)90355-O

Diamond, L. W. (1992). Stability of $\mathrm{CO}_{2}$ clathrate hydrate $+\mathrm{CO}_{2}$ liquid $+\mathrm{CO}_{2}$ vapour + aqueous $\mathrm{KCl}-\mathrm{NaCl}$ solutions: Experimental determination and application to salinity estimates of fluid inclusions. Geochimica et Cosmochimica Acta, 56, 273280. https://doi.org/10.1016/0016-7037(92)90132-3

Dias, M. A. D. (2012). Estudos de inclusões fluidas em veios de quartzo associados ao Granito Nhandu no depósito de ouro TrairãoProvíncia Aurifera Alta Floresta - MT. Dissertação (Mestrado). Cuiabá: Instituto de Ciências Exatas e da Terra, UFMT. 90p.

Galé, M. G. (2012). O depósito do Papagaio, alteração hidrotermal, regime de fluidos, geoquímica e idade, Província Aurífera de Alta Floresta-MT. Dissertação (Mestrado). Cuiabá: Instituto de Ciências Exatas e da Terra, UFMT. 96p.

Galé, M. G., Corrêa da Costa, P. C., Pinho, F. E. C., Barros, M. A. S., Juliani, C. (2015). Vulcânicas Hospedeiras da Mineralização de Ouro do Garimpo do Papagaio, Província Aurífera de Alta Floresta
(MT): Litogeoquímica e Idades. XV Simpósio Nacional de Estudos Tectônicos; IXInternational Symposium On Tectonics. Vitória: SBG.

Galé, M. G., Juliani, C. (2016). A Província Aurífera de Alta Floresta: Evolução Tectônica e Mineralizações. XLVIII Congresso Brasileiro de Geologia. Porto Alegre: SBG.

Goldstein, R. (2003). Petrographic analysis of fluid inclusions. In: I. Samson, A. Anderson, D. Marshall (Eds.), Fluid inclusions: analysis and interpretation (p. 9-53). Quebec: Mineralogical Association of Canada. (Short Course, 32).

Goldstein, R. H., Reynolds, T. J. (1994). Systematics of fluid inclusions in diagenetic minerals. Tulsa: SEPM (Society for Sedimentary Geology). Short Courses, 31, 199p.

Hart, C. J. (2005). Classifying, distinguishing and exploring for intrusion-related gold systems. Gangue, 87(1), 1-9.

Hart, C. J. R. (2007). Reduced intrusion-related gold systems. In: W. D. Goodfellow (Ed.), Mineral deposits of Canada, (v. 5, p. 95-112). Special Publication. Canada: Geological Association of Canada.

Hart, C. J. R., Goldfarb, R. J. (2005). Distinguishing intrusionrelated from orogenic gold systems. In: New Zealand Minerals Conference (Ed.), Realising New Zealand's mineral potential: proceedings (p. 125-133). Auckland: New Zealand Minerals Conference.

Japan International Cooperation Agency (JICA), Metal Mining Agency of Japan (MMAJ). (2000) Report on the mineral exploration in the Alta Floresta area, Federative Republic of Brazil: final report. Tóquio: Japan International Cooperation Agency. Metal Mining Agency of Japan. 137 p.

Juliani, C., Carneiro, C. C., Carreiro-Araújo, S. A., Fernandes, C. M. D., Monteiro, L. V. S., Crósta, A. P. (2013). Estruturação dos arcos magmáticos paleoproterozoicos na porção sul do Cráton Amazônico: Implicações geotectônicas e metalogenéticas. XIII Simpósio de Geologia da Amazônia. Belém: SBG [CD-ROM].

Juliani, C., Carneiro, C. C., Fernandes, C. M. D., Monteiro, L. V. S., Crósta, A. P., Carreiro-Araújo, S. A., Echeverri-Misas, C. M., Tokashiki, C. C., Aguja-Bocanegra, M. A. (2014). Arcos magmáticos continentais paleoproterozoicos superpostos na porção sul do Cráton Amazônico. XLVII Congresso Brasileiro de Geologia. Salvador: SBG [CD-ROM].

Juliani, C., Rye, R. O., Nunes, C. M. D., Snee, L. W., Correa, R. H., Monteiro, L. V. S., Bettencourt, J. S., Neumann, R., Alcover Neto, A. (2005). Paleoproterozoic high-sulfidation mineralization in the Tapajós Gold Province, Amazonian craton, Brazil: geology, mineralogy, alunite argon age and stable isotopes constraints. 
Chemical Geology, 215(1), 95-125. https://oi.org/10.1016/j. chemgeo.2004.06.035

Lacerda Filho, J. V., Abreu Filho, W., Valente, R. C., Oliveira, C. C., Albuquerque, M. C. (2004). Geologia e recursos minerais do Estado de Mato Grosso. Cuiabá: Programa de Geologia do Brasil, CPRM.

Leite, J.A. D., Saes, G. S. (2003). Geocronologia Pb/Pb de zircões detríticos e análise estratigráfica das coberturas sedimentares proterozoicas do Sudoeste do Cráton Amazônico. Geologia USP. Série Cientifica, 3(1), 113-127. http://dx.doi.org/10.5327/ S1519-874X2003000100009

Lowenstern, J. B. (2001). Carbon dioxide in magmas and implications for hydrothermal systems. Mineralium Deposita, 36(6), 490-502. DOI: 10.1007/s001260100185

Mesquita, M. J., Teixeira, R., Trevisan, V. G., Xavier, R. P., Assis, R. R., Quispe, P., Moreto, M., Schmidit, V., Matos, J. H. S. N., Agnoleto, E., Paes de Barros, A. J., Miguel-Jr, E. (2015). Gold deposits in ductile shear zone of the Paleoproterozoic Alta Floresta Province (Brazil). 13 ${ }^{\text {th }}$ SGA Biennial Meeting. Nancy: SGA.

Moura, M. A. (1998). O maciço granítico Matupá no Depósito de ouro Serrinha (MT): petrologia, alteração hidrotermal e metalogenia. Tese (Doutorado). Brasília: Instituto de Geociências, UnB. 241p.

Moura, M. A., Botelho, N. F., Olivo, G. R., Kyser, T. K. (2006). Granite-related Paleoproterozoic, Serrinha gold deposit, Southern Amazonia, Brazil: hydrothermal alteration, fluid inclusion and stable isotope constraints on genesis and evolution. Economic Geology, 101, 585-605. https://doi.org/10.2113/ gsecongeo.101.3.585

Nagase, T. E., Kojima, S. (1997). An SEM examination of the chalcopyrite disease texture and its genetic implications. Mineralogical Magazine, 61(1), 89-97.

Paes de Barros, A. J. (2007). Granitos da região de Peixoto de Azevedo-Novo Mundo e mineralizações auríferas relacionadasProvíncia Aurifera Alta Floresta (MT). Tese (Doutorado). Campinas: Instituto de Geociências, Unicamp. 154p.

Pessoa, M. R., Santiago, A, F., Andrade, A. F., Nascimento, J. O., Santos, J. O. S., Oliveira, J. R., Lopes, R. C., Prazeres, W. V. (1977). Projeto Jamanxim: Relatório Final. Manaus: CPRM, Superintendência de Manaus.

Pimentel, M. M. (2001). Resultados geocronológicos do Projeto Promin Alta Floresta. Relatório Interno. Brasília: UnB.
Pirajno, F. (1992). Hydrothermal mineral deposits: principles and fundamental concepts for the exploration geologists. Berlin: Springer-Verlag.

Pirajno, F. (2009). Hydrothermal processes and mineral systems. Perth: Geological Survey of Western Australia, Springer Science Business Media B.

Quaresma, G. S., Hatanaka, T. G. T. (2011). Mapeamento litoestrutural e geoquímica do garimpo Papagaio, Província Aurífera Alta Floresta. Trabalho de Conclusão de Curso. Cuiabá: Instituto de Ciências Exatas e da Terra, UFMT. 95p.

Rambo, J. M. (2014). Controle estrutural e estudo das inclusões fluidas dos garimpos da região de Terra Nova do Norte e Nova Santa Helena, Província Aurífera Alta Floresta, Cráton Amazônico. Dissertação (Mestrado). Cuiabá: Instituto de Ciências Exatas e da Terra, UFMT. 146p.

Rodrigues, R. M. (2012). Caracterização geológica e metalogenética do Depósito X1 - Província Aurífera de Alta Floresta, Região de Matupá (MT). Dissertação (Mestrado). Campinas: Instituto de Geociências, Unicamp. 70p.

Roedder, E. (1984). Reviews in mineralogy volume 12: fluid inclusions. Virginia: Mineralogical Society of America.

Santos, J. O. S., Groves, D. I., Hartmann, A., Moura, M. A., McNaughton, N. J. (2001). Gold deposits of the Tapajós and Alta Floresta domains, Tapajós-Parima orogenic belt, Amazon Craton, Brazil. Mineralium Deposita, 36(3-4), 278-299. DOI: $10.1007 / \mathrm{s} 001260100172$

Santos, J. O. S., Hartmann, L. A., Gaudette, H. E., Groves, D. I., McNaughton, N. J., Fletcher, I. R. (2000). A new understanding of the Provinces of the Amazon Craton based on integration of field mapping an $\mathrm{U}-\mathrm{Pb}$ and $\mathrm{Sm}-\mathrm{Nd}$ geochronology. Gondwana Research, 3(4), 453-488. DOI: 10.1016/S1342-937X(05)70755-3

Santos, J. O. S., Hartmann, L. A., Riker, S. R., Souza, M. M., Almeida, M. E., Mcnaughton, N. J. (2006). A compartimentação do Cráton Amazonas em províncias: avanços ocorridos no período 2000-2006. IX Simpósio de Geologia da Amazônia. Belém: SBG [CD-ROM].

Seedorff, E., Dilles, J. H., Proffett Jr., J. M., Einaudi, M. T., Zurcher, L., Stavast, W. J. A., Johnson, D. A., Barton, M. D. (2005). Porphyry deposits: characteristics and origin of hypogene features. Economic Geology, $100^{\text {th }}$ Anniversary volume, 251-298. https://doi.org/10.5382/ AV 100.10 
Serrato, A. A. A. (2014). Geocronologia e evolução do sistema hidrotermal do depósito aurífero de Juruena, Província Auriffera de Alta Floresta (MT), Brasil. Dissertação (Mestrado). Campinas: Instituto de Geociências, Unicamp. 66p.

Sillitoe, R. H. (2010). Porphyry copper systems. Economic Geology, 105(1), 3-41. https://doi.org/10.2113/ gsecongeo.105.1.3

Silva, M. G., Abram, M. B. (2008). Projeto metalogenia da Província Aurifera Juruena-Teles Pires, Mato Grosso. Goiânia: Serviço Geológico Brasileiro, CPRM.

Sinclair, W. D. (2007). Porphyry deposits. In: W. D. Goodfellow (Ed.), Mineral Deposits of Canada: a synthesis of major deposit-types, district metallogeny, the evolution of geological provinces, and exploration methods (v. 5, p. 223-243). Littleton: Economic Geology. Canadá: Geological Association of Canada, Mineral Deposits Division, Special Publication.

Souza, J. P., Frasca, A. A. S., Oliveira, C. C. (2005). Geologia e recursos minerais da Província Mineral de Alta Floresta. Brasília: Serviço Geológico Brasileiro, CPRM.

Sun, W., Huang, R., Li, H., Hu, Y. B., Zhang, C. C., Sun, S. J., Zhang, L. P., Ding, X., Li, C., Zartman, R. E., Xing Ling, M. (2015). Porphyry deposits and oxidized magmas. Ore Geology Reviews, 65(1), 97-131. https://doi.org/10.1016/j. oregeorev.2014.09.004

Tassinari, C. C. G. (1996). O mapa geocronológico do Cráton Amazônico no Brasil: Revisão dos Dados Isotópicos.
Tese (Livre-Docência). São Paulo: Instituto de Geociências, USP. 139 p.

Tassinari, C. C. G., Macambira, M. J. B. (1999). Geochronological Provinces of the Amazonian Craton. Episodes, 22(3), 174-182.

Tassinari, C. G. C., Macambira, M. J. B. (2004). A evolução tectônica do Cráton Amazônico. In: V. Neto-Mantesso, A. Bartorelli, C. D. R. Carneiro, B. B. Brito-Neves (Eds.), Geologia do continente sul-americano: evolução da obra de Fernando Flávio Marques de Almeida (v. 1, p. 471-486). São Paulo: Beca.

Taylor, B. E. (2007). Epithermal gold deposits. In: W. D. Goodfellow (Ed.), Mineral deposits of Canada: a synthesis of major deposit-types, district metallogeny, the evolution of geological provinces, and exploration methods (v. 5, p. 113-139). Littleton: Economic Geology. Canadá: Geological Association of Canada, Mineral Deposits Division, Special Publication.

Trevisan, V. G. (2015). Estudo comparativo entre mineralizações filonares de $\mathrm{Au} \pm \mathrm{Cu}$ e $\mathrm{Au}+$ metais de base do setor leste da Província de Alta Floresta (MT), Cráton Amazônico. Dissertação (Mestrado). Campinas: Instituto de Geociências, Unicamp. 129 p.

Xavier, R. P., Assis, R. R., Miguel-Jr, E., Santos, T. J. S., Paes de Barros, A. J. (2011). Gold \pm copper and goldbase metal deposits associated with granitic systems in the eastern sector of the Alta Floresta Province. XII Simpósio de Geologia da Amazônia. Roraima: SBG [CD-ROM]. 